\title{
Pejvakin, a Candidate Stereociliary Rootlet Protein, Regulates Hair Cell Function in a Cell-Autonomous Manner
}

\author{
Darcin Kazmierczak, ${ }^{1 \star}$ Piotr Kazmierczak, ${ }^{2 \star}{ }^{\circledR}$ Anthony W. Peng, ${ }^{3,4}$ Suzan L. Harris, ${ }^{1}$ Prahar Shah, ${ }^{1}$ Jean-Luc Puel, ${ }^{2}$ \\ Marc Lenoir, ${ }^{2}$ SSantos J. Franco, ${ }^{5}$ and Martin Schwander ${ }^{1}$ \\ ${ }^{1}$ Department of Cell Biology and Neuroscience, Rutgers the State University of New Jersey, Piscataway, New Jersey 08854, ${ }^{2}$ Inserm U1051, Institute for \\ Neurosciences of Montpellier, 34091, Montpellier cedex 5, France, ${ }^{3}$ Department of Otolaryngology, Head and Neck Surgery, Stanford University, Stanford, \\ California 94305, ${ }^{4}$ Department of Physiology and Biophysics, University of Colorado School of Medicine, Aurora, Colorado 80045, and ${ }^{5}$ Department of \\ Pediatrics, University of Colorado School of Medicine, Aurora, Colorado 80045
}

Mutations in the Pejvakin (PJVK) gene are thought to cause auditory neuropathy and hearing loss of cochlear origin by affecting noise-induced peroxisome proliferation in auditory hair cells and neurons. Here we demonstrate that loss of pejvakin in hair cells, but not in neurons, causes profound hearing loss and outer hair cell degeneration in mice. Pejvakin binds to and colocalizes with the rootlet component TRIOBP at the base of stereocilia in injectoporated hair cells, a pattern that is disrupted by deafness-associated PJVK mutations. Hair cells of pejvakin-deficient mice develop normal rootlets, but hair bundle morphology and mechanotransduction are affected before the onset of hearing. Some mechanotransducing shorter row stereocilia are missing, whereas the remaining ones exhibit overextended tips and a greater variability in height and width. Unlike previous studies of $P j v k$ alleles with neuronal dysfunction, our findings reveal a cell-autonomous role of pejvakin in maintaining stereocilia architecture that is critical for hair cell function.

Key words: auditory neuropathy spectrum disorder; DFNB59; hair cell; hearing loss; inner ear; pejvakin

\section{Significance Statement}

Two missense mutations in the Pejvakin (PJVK or DFNB59) gene were first identified in patients with audiological hallmarks of auditory neuropathy spectrum disorder, whereas all other $P J V K$ alleles cause hearing loss of cochlear origin. These findings suggest that complex pathogenetic mechanisms underlie human deafness DFNB59. In contrast to recent studies, we demonstrate that pejvakin in auditory neurons is not essential for normal hearing in mice. Moreover, pejvakin localizes to stereociliary rootlets in hair cells and is required for stereocilia maintenance and mechanosensory function of the hair bundle. Delineating the site of the lesion and the mechanisms underlying DFNB59 will allow clinicians to predict the efficacy of different therapeutic approaches, such as determining compatibility for cochlear implants.

\section{Introduction}

Our sense of hearing depends on the exquisite sensitivity of cochlear hair cells to sound-induced deflections of their apical

Received Aug. 26, 2016; revised Jan. 2, 2017; accepted Jan. 25, 2017

Author contributions: M.K., P.K., A.W.P., S.L.H., P.S., J.-L.P., M.L., S.J.F., and M.S. designed research; M.K., P.K., A.W.P., S.L.H., P.S., J.-L.P., M.L., S.J.F., and M.S. performed research; S.J.F. contributed unpublished reagents/ analytic tools; M.K., P.K., A.W.P., S.L.H., P.S., J.-L.P., M.L., S.J.F., and M.S. analyzed data; M.K., P.K., and M.S. wrote the paper.

This work was supported by National Institutes of Health Grant DC013331 to M.S., Rutgers State University of New Jersey to M.S., Busch Biomedical Grant to M.S., Capita Foundation for Hearing Research Fellowship to M.S., National Institutes of Health Grant DC003896 to Anthony Ricci, and National Institutes of Health Grant DC013299 to A.W.P. The generation of the floxed Pjvk allele was performed with funding from the National Institute on Deafness and Other Communication Disorders DC014713 and DC007704 to Ulrich Mueller. This work was also supported by Inserm Grant U1051-Dot 02 and Fondation Gueules Cassées 09-2014. P.K. is a recipient of a Montpellier University postdoctoral fellowship. We thank Nadiya Chuchvara, Clare Cutri-French, and other members of the M.S. laboratory for helpful discussions; Ulrich Mueller for kindly supplying the Otof-Cre mouse strain; Wei Xiong for advice on injectoporation techniques; Lisa Goodrich for Ngn1-CreER ${ }^{T 2}$ mice; Thomas Friedman and Inna Belyantseva for sup- hair bundles. Hair bundles consist of an array of F-actin rich stereocilia that are organized in rows of increasing height, with a staircase-like geometry (Tilney et al., 1992a, b). Deflection of the bundle toward its tall edge imparts tension on tip links, which increases the open probability of mechanotransduction channels at the lower end of each tip link (Pickles et al., 1984; Howard and Hudspeth, 1988; Assad et al., 1991). Each stereocilium is tapered at its base and anchored into the cuticular plate with a rootlet that provides mechanical durability during

plying the TRIOBP-5 and TRIOBP-4/5 antisera; and Chantal Cazvieille and Alicia Caballero (Technological Plateau COMET of Montpellier) for help with electron microscopy and preparation of TEM sections.

The authors declare no competing financial interests.

*M.K. and P.K. contributed equally to this work.

Correspondence should be addressed to Dr. Martin Schwander, Rutgers State University of New Jersey, 604 Allison Road, Piscataway, NJ 08854. E-mail: schwander@biology.rutgers.edu.

DOI:10.1523/JNEUROSCI.2711-16.2017

Copyright $\odot 2017$ the authors $\quad 0270-6474 / 17 / 373447-18 \$ 15.00 / 0$ 
acoustic stimulation (Furness et al., 2008; Kitajiri et al., 2010). Although many protein constituents of hair bundles have been identified, the molecules that function at the base of stereocilia and their role in hair-bundle morphogenesis and function are largely unknown.

Hereditary deafness is a genetically heterogeneous disorder. To date, $>150$ loci for monogenic hearing loss have been reported (http://hereditaryhearingloss.org). Importantly, different mutations in the same gene often cause distinct disease phenotypes (Astuto et al., 2002; Zhao et al., 2011). This is well exemplified by DFNB59, a recessive form of sensorineural hearing loss, caused by mutations in the PJVK gene (encoding pejvakin) (Delmaghani et al., 2006). Pejvakin is a distantly related member of the gasdermin protein family (Saeki et al., 2000). Gasdermins share a common N-terminal domain (gasdermin domain) of unknown function. Missense mutations in PJVK (p. T54I or p.R183W) were first identified in patients with auditory neuropathy spectrum disorder (ANSD) (Delmaghani et al., 2006), a hearing disorder characterized by abnormal transmission of signals by the auditory nerve in combination with apparently normal outer hair cell (OHC) function (Starr et al., 1996; Kemp, 2002). The pathophysiology of ANSD includes defects either in the inner hair cells (IHCs), the synapses between IHCs and afferent dendrites of the auditory nerve, or the nerve itself. ANSD patients present with abnormal auditory brainstem responses (ABRs) and preserved otoacoustic emissions (OAEs), an indication of functional OHCs. Likewise, Pjvk p.R183W knock-in mice showed elevated auditory thresholds, increased ABR interpeak latencies, and normal OAEs (Delmaghani et al., 2006). It was therefore hypothesized that pejvakin regulates neuronal function. Consistent with this idea, pejvakin antisera labeled auditory neurons, but also hair cells and supporting cells in the cochlea (Delmaghani et al., 2006). Yet, the specificity of these antisera has recently been questioned by the same group (Delmaghani et al., 2015).

Studies of an ENU-generated mouse model for DFNB59, termed sirtaki, revealed more complex mechanisms of pathogenesis (Schwander et al., 2007). Surprisingly, sirtaki mice showed $\mathrm{OHC}$ dysfunction and progressive hearing loss due to a nonsense mutation (p.K290X) that deletes a predicted C-terminal Znbinding motif. The perception that pejvakin is functional only in neurons has also been challenged by the finding that Pjvk mRNA was detected exclusively in hair cells (Schwander et al., 2007). In addition, Collin et al. (2007) described OHC defects in a Turkish family that carry the same DFNB59 missense mutation (p.R183W) reported in the original ANSD study (Delmaghani et al., 2006). Although differences in genetic background or age of the tested individuals may account for some of the phenotypic variability, the findings clearly suggest that pejvakin is critical for hair cell function.

Recent studies have ascribed a role for pejvakin in the oxidativestress induced proliferation of peroxisomes in hair cells and auditory neurons in response to noise exposure (Delmaghani et al., 2015). Using novel Pjvk conditional knock-out alleles, we show that pejvakin in neurons is not essential for auditory function. By contrast, pejvakin is required for normal mechanotransduction in hair cells before the onset of hearing. Finally, we demonstrate that pejvakin selectively localizes to stereociliary rootlets and is required to preserve the integrity of mechanosensitive stereocilia, indicative of a role for this gasdermin in hair bundle maintenance and function.

\section{Materials and Methods}

Mouse strains and ABR measurement

All procedures were performed in accordance with research guidelines of the institutional animal care and use committee of Rutgers University. Mice of either sex were studied. To generate $P j v k^{\mathrm{fl}}$ mice, a gene-targeting vector was generated to insert LoxP sites flanking exon 1 of the Pjvk gene, followed by a neomycin-resistance cassette ( $P G K$-neo) flanked by two FRT sites. The vector was electroporated into C57BL/6J embryonic stem cells. Targeted embryonic stem cell clones were screened by PCR for recombination of the $3^{\prime}$ arm (SP1: 5'-GCTACCCGTGATATTGCTGAAGAGCT and SP2: 5'CACAAGTGGAAGGAGAAAACTGAGTC) and the presence of the $5^{\prime}$ LoxP site (LP1: 5'-GATCTGCACCCAATTGTTTTTCT and LP2: 5'ACTCAGGGGTTGGTACTTGTCAGC). One confirmed clone was injected into C57BL/6J blastocysts to generate chimera, which were mated to C57BL/6J females to obtain germline transmission. Heterozygous F1 mice $\left(P j v k^{\mathrm{fl}-\mathrm{neo} /+}\right)$ were mated with B6.Cg-Tg(ACTFLPe) mice (The Jackson Laboratory, stock \#005703) to remove the pGK-neomycin selection cassette, and the resulting offspring were subsequently mated to C57BL/6J mice to remove the FLPe transgene. Crossing heterozygous mice generated Pjvk $k^{\mathrm{f} / \mathrm{fl}}$ mice, and genotyping was performed by PCR on tail DNA. Detection of floxed allele: FF: 5'-GAATTCCTCTTGGATGATGGCCACTGCAGA and FR: 5'-AACGAAGCTCTTGGTAGCAGCAGCAAACAT.

Otof-Cre mice (kindly supplied by Dr. Ulrich Mueller, Scripps Research Institute) were generated as described elsewhere (https://www.mmrrc.org/ catalog/sds.php?mmrrc_id=32781). In brief, a targeting vector was designed to insert a nuclear-localized Cre recombinase gene and polyA signal followed by an FRT-flanked PGK-Neo cassette into the initiation codon of the otoferlin (Otof) locus. This construct was electroporated into C57BL/6Jderived Bruce4 embryonic stem cells. Chimeric mice were bred to albino C57BL/6J (B6(Cg)-Tyrc-2J/J) mice to establish the colony. Next, mutant mice were bred with FLPe-expressing mice on a C57BL/6J congenic background to remove the FRT-flanked PGK-Neo cassette. The resulting OtofCre mice were then bred to C57BL/6J inbred mice for approximately two generations, selecting away the FLPe transgene. Ngn1-CreER ${ }^{\mathrm{T} 2}$ transgenic mice were a kind gift from Dr. Lisa Goodrich (Harvard Medical School) (Koundakjian et al., 2007). Nestin-Cre transgenic driver mice, Ai9/tdTomato

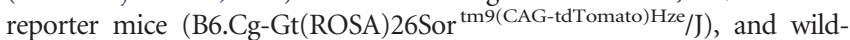
type C57BL/6J mice were obtained from The Jackson Laboratory. Pjvk $k^{\mathrm{f} / \mathrm{fl}}$ mice were mated to Nestin-Cre transgenic mice (Tronche et al., 1999; GrausPorta et al., 2001), Otof-Cre mice, and Ngn1-CreER ${ }^{\mathrm{T} 2}$ mice (Koundakjian et al., 2007), which were genotyped as previously described (Graus-Porta et al., 2001). Double heterozygous Pjvk $\mathrm{fl}^{\mathrm{l} /+}$; Nestin-Cre; Pjvk ${ }^{\mathrm{fl} /+} ;$ Otof-Cre; and $P j v k^{\mathrm{l} / /+} ; N_{g n 1-C r e E R}{ }^{\mathrm{T} 2}$ mice were crossed with homozygous $P j v k^{\mathrm{fl} / \mathrm{fl}}$ mice to obtain animals used in experiments. To avoid pleiotropic effects due to potential germline deletion of loxP-flanked pejvakin gene and to maintain the CNS-restricted deletion status in Nestin-Pjvk conditional knockout (cKO) mouse colonies, we performed PCR-based genotyping of mouse tail DNA to detect Cre-mediated excision of exon 1 of the Pjvk gene. Detection of Pjvk null allele: FF and NR: 5' -GAATTCCTCTTGGATGATGGCCACTGC AGA. We further genotyped mice for the presence of the pejvakin floxed allele to distinguish between heterozygous and homozygous pejvakin null mice. To induce Cre activity in crosses with Ngn1-CreER ${ }^{\mathrm{T} 2}$ mice, pregnant females at E10.5 were intraperitoneally injected with $12.5 \mu \mathrm{g}$ per gram 4-hydroxytamoxifen (Sigma), dissolved using Kolliphor EL (Sigma) as described previously (Chevalier et al., 2014). The measurement of ABRs and distortion product otoacoustic emissions (DPOAEs) followed our published procedures (Schwander et al., 2007).

\section{Immunohistochemistry and electron microscopy}

Whole-mount staining of cochlear sensory epithelia was performed as described previously (Senften et al., 2006; Schwander et al., 2007). Commercially available (Sigma, \#HPA042621 and Santa Cruz Biotechnology, \#167621) and custom rabbit polyclonal anti-pejvakin antibodies directed against two coinjected peptides of mouse pejvakin (QVGDGGRLVPVPS LS, DEQNPKGREKAIVFPAHT) were tested for their specificities on HeLa cells transfected with an expression vector ( $\mathrm{pEGFP-N1}$, Clontech) encoding full-length pejvakin fused to EGFP. Protein expression was evaluated by immunofluorescence analysis with anti-pejvakin antibodies as described previously (Senften et al., 2006). TRIOBP-5 antisera were a 
kind gift from Dr. Thomas Friedman (National Institutes of Health, Bethesda, MD). Additional antibodies were as follows: anti-myosin VIIa (rabbit; Proteus Biosciences), anti-taperin (rabbit, Sigma), anti-PMP70 (rabbit, ab3421, Abcam), anti-Tuj1 (rabbit; Abgent), anti-cleaved Caspase-3 (rabbit; Cell Signaling Technology), anti-GFP (chicken; Rockland), anti-GFP (rabbit; Abcam), anti-FLAG HRP conjugate (mouse, Sigma), AlexaFluor-488, -568, and -647 anti-rabbit and anti-mouse (Invitrogen), AlexaFluor-488 anti-chicken (Invitrogen) and AlexaFluor350, AlexaFluor-488, and phalloidin 647 (Invitrogen), and HRP-conjugated anti-rabbit (GE Healthcare).

For both scanning electron microscopy (SEM) and transmission electron microscopy (TEM), cochleae were rapidly removed, gently perfused through the round and oval windows with $2.5 \%$ glutaraldehyde in $0.1 \mathrm{M}$ phosphate buffer, $\mathrm{pH} 7.4$, and immersed in the same solution for $1 \mathrm{~h}$ at room temperature. For SEM, cochleae were next perfused with $0.2 \mathrm{M}$ phosphate buffer and immersed over $30 \mathrm{~min}$ at room temperature. Specimens were stored and shipped in $0.1 \%$ glutaraldehyde in $0.2 \mathrm{M}$ phosphate buffer. The cochlear shell bone was shaved off and partially removed, together with the stria vascularis, the Reissner's membrane, and the tectorial membrane, to expose the apical surface of the organ of Corti. The specimens were, dehydrated through ethanol, critical point dried with $\mathrm{CO}_{2}$, and coated with gold. Imaging was performed on a Hitachi S4000 scanning electron microscope. For TEM, cochleae were postfixed in a $2 \%$ aqueous solution of osmium tetroxide for $1 \mathrm{~h}$ at room temperature, washed in the buffer, dehydrated, and embedded in Epon resin. Transverse ultrathin sections of the organ of Corti were mounted on formvar-coated grids, stained with uranyl acetate and lead citrate, and observed using a Hitachi 7100 microscope. Adobe Photoshop was used to adjust the contrast of the images and to measure the dimensions of the IHC stereocilia.

\section{In situ hybridization}

In situ hybridization was performed on $12-\mu \mathrm{m}$-thick cryosections, as described previously (Schwander et al., 2007; Grillet et al., 2009). The RNA probe is complementary to full-length mouse pejvakin cDNA (NCBI: NM_001080711.2).

DNA constructs, immunoprecipitations, and Western blot analysis The apparent full-length cDNA encoding mouse pejvakin (352 aa) was amplified from cochlear RNA by RT-PCR and inserted in frame into BamHI/XhoI sites of pcDNA3 and XhoI/BamHI sites of pEGFP-N1 (Clontech) vectors. To generate HA-PJVK, PJVK-HA, and PJVK-FLAG, the FLAG- or HA-tag sequences were included in the forward or reverse primer and the product of PCR amplification was inserted into pcDNA3 vector using BamHI/XhoI sites. The point mutation (C343S) was introduced into pEGFP-N1-pejvakin using the site-directed mutagenesis kit (Stratagene). PCR-generated deletion mutants (K290X, GSDM) and C-terminal domain (aa 241-352) of pejvakin were cloned into XhoI/ BamHI sites of pEGFP-N1 vector, and XhoI/BamHI sites of pEGFP$\mathrm{N} 1$ and pEGFP-C1 vectors, respectively. The cDNA encoding mouse TRIOBP1 (627 aa) was amplified from cochlear RNA by RT-PCR and inserted in frame into XhoI/BamHI sites of pEGFP-N1 and pEGFP-C1 vectors. For TRIOBP1-HA, the HA-tag sequence was included in the reverse primer and the product of PCR amplification was inserted into pcDNA3.1 vector using XhoI /BamHI sites. PCR-generated deletion mutants of TRIOBP1, including pleckstrin homology (PH) domain (aa 49320 ), mid-to-coiled-coil (midCC) region (aa 157-657), and coiled-coil (CC) domain (aa 314-657), were cloned into BamHI/NotI sites of pGEX-4T1 vector. HEK293 cells were transiently transfected using X-tremeGENE 9 DNA transfection reagent (Roche) according to the manufacturer's instructions. Cell lysis, immunoprecipitations with antiGFP antibody (rabbit, Sigma), and Western blot analysis were performed as described previously (Kazmierczak et al., 2015), except that cellular extracts were prepared in $50 \mathrm{~mm}$ Tris- $\mathrm{HCl}, \mathrm{pH} 7.6,150 \mathrm{~mm} \mathrm{NaCl}, 1 \%$ $\mathrm{NP}-40$, and immunocomplexes washed three times in $50 \mathrm{~mm}$ Tris- $\mathrm{HCl}$, pH 7.6, $150 \mathrm{~mm} \mathrm{NaCl}$, and $0.25 \% \mathrm{NP}-40$. The blots were probed with anti-GFP (rabbit, Sigma) and anti-HA-HRP (rat, Roche) antibodies. Primary antibodies and proteins were visualized with HRP-conjugated antirabbit antibody (1:20,000, GE Healthcare) using the ECL2 detection system (Thermo Fisher Scientific).
GST pull-down assays

GST-TRIOBP-PH (aa 49-320), GST-TRIOBP-CC (aa 314-627), and GST-TRIOBP-midCC (aa 157-627) fusion proteins were produced in Escherichia coli BL21 cells (EMD Millipore) and affinity purified using glutathione-Sepharose 4B beads (GE Healthcare). Approximately $4 \mu \mathrm{g}$ of purified GST fusion proteins was incubated for $4 \mathrm{~h}$ with in vitro-transcribed/translated HA-PJVK and HA-phosphoglycerate kinase 1 (PGK1) proteins (TNT; Promega) at $4^{\circ} \mathrm{C}$ in $0.5 \mathrm{ml}$ of buffer A ( $50 \mathrm{~mm}$ Tris- $\mathrm{HCl}$, pH 7.6, $100 \mathrm{~mm} \mathrm{NaCl}, 0.1 \mathrm{~mm}$ EDTA, $0.2 \%$ Triton X-100, $0.1 \%$ $\beta$-mercaptoethanol, $1 \mathrm{~mm}$ PMSF), supplemented with MS SAFE protease and phosphatase inhibitor mixture (1:100, Sigma). The beads were washed four times with $0.7 \mathrm{ml}$ of ice-cold buffer B (50 mM Tris- $\mathrm{HCl}, \mathrm{pH}$ 7.6, $100 \mathrm{~mm} \mathrm{NaCl}, 0.1 \mathrm{~mm}$ EDTA, 0.2\% Triton X-100, 1 mM PMSF), and $\operatorname{MS} \operatorname{SAFE}(1 ; 100$, Sigma $)$ at $4^{\circ} \mathrm{C}$. Proteins bound to beads were denatured in Laemelli sample buffer and subjected to SDS-PAGE and Western blotting. The blots were probed with anti-HA-HRP (rat, Roche) and antiGST-HRP (goat, Abcam) antibodies and analyzed using the ECL2 detection system (Thermo Fisher Scientific).

\section{Culture and injectoporation of cochlear explants}

Injectoporation of cochlear explants was performed following recently established protocols (Xiong et al., 2014). In brief, cochleae were dissected from postnatal (P) day 4 and P5 wild-type mice, cut into three pieces, and cultured for $4 \mathrm{~h}$ in DMEM/F12 medium with $10 \mathrm{ng} / \mu \mathrm{l}$ ampicillin. Next, adherent cochlear explants were placed between two platinum wire electrodes (Surepure Chemetals) and injected with plasmid (1 $\mu \mathrm{g} / \mu \mathrm{l}$ ) between the second and third row of OHCs using a patch pipette (2-3 $\mu \mathrm{m}$ diameter). Pipette and electrode were positioned using a BX51 upright microscope with a $60 \times$ objective (Olympus), and two micromanipulators (Sutter MPC-200). Next, 3-5 square-pulses with a magnitude of $60 \mathrm{~V}$ (15 ms length, $1 \mathrm{~s}$ intervals) were applied, using an ECM 830 electroporator (Harvard Apparatus). Organs of Corti were cultured for another $12 \mathrm{~h}$ in DMEM/F12 and fixed in 4\% PFA for 40 min before immunostaining. Samples were analyzed using a BX63 fluorescence microscope and cellSens software (Olympus).

\section{Mechanoelectrical transduction (MET) recordings}

Preparation and recordings. Animals were killed by decapitation using methods approved by the Stanford University Administrative Panel on Laboratory Animal Care. Organs of Corti were dissected from P7-P10 mice and placed in recording chambers as previously described (Beurg et al., 2009). Tissue was viewed using a $60 \times(1.0 \mathrm{NA}$, Olympus) or $100 \times$ (1.0 NA, Olympus) water-immersion objective on a BX51 microscope (Olympus). Tissue was dissected and perfused with external solution containing the following (in $\mathrm{mM}$ ): $140 \mathrm{NaCl}, 2 \mathrm{KCl}, 2 \mathrm{CaCl}_{2}, 2 \mathrm{MgCl}_{2}, 10$ HEPES, 2 creatine monohydrate, 2 Na-pyruvate, 2 ascorbic acid, 6 dextrose, $\mathrm{pH} 7.4,300-310 \mathrm{mOsm}$. In all preparations, the tectorial membrane was peeled off the tissue.

Electrophysiological recordings. Whole-cell patch clamp was achieved first or second row OHCs from middle to apical cochlea turns using an Axon 200B amplifier (Molecular Devices) with thick-walled borosilicate patch pipettes (2-6 $\mathrm{M} \Omega$ ) filled with an intracellular solution containing the following (in mM): $121 \mathrm{CsCl}, 3.5 \mathrm{MgCl}_{2}, 5 \mathrm{ATP}, 5$ creatine phosphate, 10 HEPES, 2 ascorbate, 1 EGTA, pH 7.2, 280-290 mOsm. Experiments were performed at $18^{\circ} \mathrm{C}-22^{\circ} \mathrm{C}$. Whole-cell currents were filtered at 10 $\mathrm{kHz}$ and sampled at $0.05-1 \mathrm{MHz}$ using USB-6356 (National Instruments) controlled by jClamp (SciSoft). Cells were voltage clamped at -80 , not accounting for liquid junction potentials.

Stiff probe hair bundle stimulation. Borosilicate pipettes were fire polished to various shapes to test the effect of probe shape. These glass probes were mounted in an aluminum holder attached to a piezoelectric stack (AE0505D08F, Thorlabs; or PSt 150/7x7/7, APC International) driven by a high voltage/high current amplifier. Step stimuli were filtered with an 8-pole Bessel filter (L8L 90PF, Frequency Devices) at $5-10 \mathrm{kHz}$ and variably attenuated (PA5, Tucker Davis) before reaching the piezo amplifier.

Data analysis. IX plots were generated by subtracting leak current and normalizing to the peak current. IX plots were fit to a double Boltzmann equation as follows: 

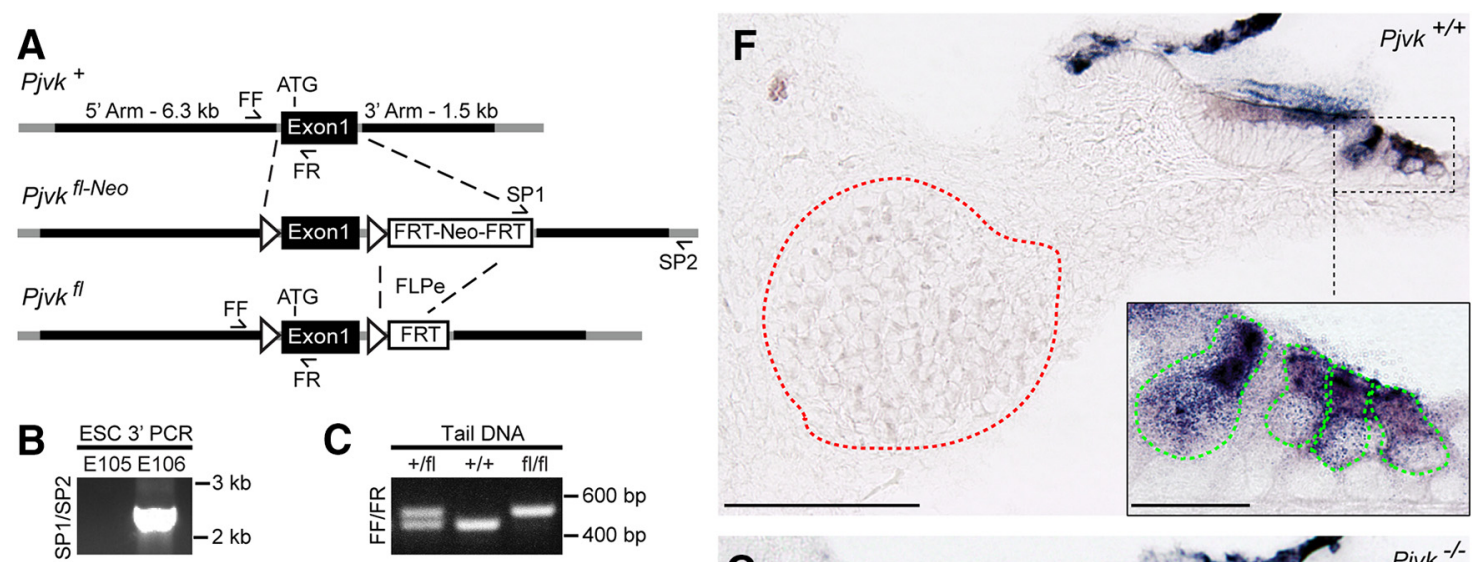

D

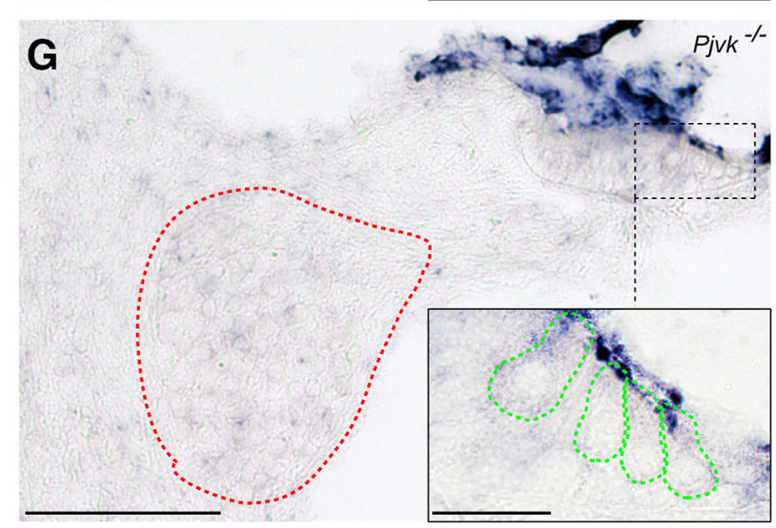

Figure 1. Generation of a conditional Pjvk allele. A, Schematic representation of the three alleles of the Pjvk gene: wild-type $(+)$, targeting construct ( fl-Neo), and floxed allele of Pjvk conditional knock-in mouse obtained after removal of Neo cassette with flippase ( $f$ ) $) .5^{\prime}$ and $3^{\prime}$ homology arms used for targeted recombination (black regions), loxP sites (triangles), and genotyping primers (SP1, SP2, FF, FR) are indicated. B, PCR analysis of wild-type (E105) and targeted (E106) ES cells with SP1/SP2 primers. C, PCR analysis of Pjvk ${ }^{+/ f l}$, Pjvk ${ }^{+/+}$, and Pjvk ${ }^{f / f l}$ mouse with FF/FR primers. $D$, Schematic illustration of Cre-mediated excision of exon1 upon rare germline Nestin-Cre expression that led to the generation of $P_{j v k^{-1-}}$ mice. $E$, Two pairs of genotyping primers, whose positions are indicated in $\boldsymbol{D}$, are used to distinguish between $P j v k^{+/-}, P j v k^{-/-}$, and $P j v k^{+/+}$mice: the presence of $P j v k^{+}$and $P j v k^{-}$alleles is detected with FF/FR and FF/NR genotyping, respectively. $\boldsymbol{F}, \boldsymbol{G}$, Analysis of Pjvk mRNA expression in cochlear sections from P4 Pjvk ${ }^{+/+}(\boldsymbol{F})$ and Pjvk ${ }^{-/-}(\boldsymbol{G})$ mice by ISH. Pjvk is specifically expressed in hair cells of Pjvk ${ }^{+/+}$, but not Pjvk ${ }^{-/-}$mice (green dashed line). Despite long incubation, resulting in nonspecific hybridization signal in the tectorial and Reissners' membranes, there was no detectable Pjvk expression in the spiral ganglion of $P j v k^{+/+}$mice (red dashed line). Scale bars: $\boldsymbol{F}, \mathbf{G}, 100 \mu \mathrm{m}$; Insets, $20 \mu \mathrm{m}$.

$$
y=\frac{I_{\max }}{1+e^{z_{2}\left(x_{0}-x\right)}\left(1+e^{z_{1}\left(x_{0}-x\right)}\right)}
$$

where $Z_{1}$ and $Z_{2}$ are the slope factors and $x_{0}$ represents the operating point. Data were analyzed using jClamp, MATLAB (The MathWorks), and Microsoft Excel. Graphs were created using MATLAB, Origin 8.6 (OriginLabs), and Adobe Illustrator.

\section{Results}

Generation of pejvakin-flox mice

Although DFNB59 was initially characterized as auditory neuropathy (Delmaghani et al., 2006), subsequent studies revealed mutations in PJVK that cause OHC dysfunction (Collin et al., 2007; Schwander et al., 2007), indicating that diverse pathophysiological mechanisms underlie this disorder. Based on the observations that pejvakin mRNA is selectively expressed by hair cells (Schwander et al., 2007) and that otoacoustic emissions are affected in some DFNB59 patients, we hypothesized that pejvakin regulates hair cell but not neuronal function. To determine the extent to which pejvakin regulates the function of sensory hair cells and auditory neurons, we generated mice carrying a conditional pejvakin allele $\left(P j v k^{\mathrm{fl} / \mathrm{fl}}\right)$ in which loxP sites flank the first coding exon of the Pjvk gene, which encodes part of the conserved gasdermin (GSDM) domain (Fig. $1 A-C$ ). Homozygous $P j v k^{\mathrm{fl} / \mathrm{fl}}$ mice are fertile and viable, with normal hearing and no gross anatomical defects.
To inactivate pejvakin in auditory neurons, we obtained the Ngn1-CreER ${ }^{\mathrm{T} 2}$ transgenic mouse line that allows for tamoxifeninducible Cre recombinase $\left(\mathrm{CreER}^{\mathrm{T} 2}\right)$ expression in inner ear neural precursors (Koundakjian et al., 2007) and Nestin-Cre mice (The Jackson Laboratory) that express Cre in neuronal and glial progenitor cells of the central and peripheral nervous system (Tronche et al., 1999). In accordance with previous studies (Zhang et al., 2013), we found that the Nestin-Cre transgene at a low frequency allowed transmission of a germline recombined Pjvk null allele $\left(P j v k^{-1-}\right)$ to offspring (Fig. $1 D, E)$. Subsequent breeding and genotyping allowed us to generate $P j v k^{-1-}$ mice. Following germline recombination, Pjvk mRNA was no longer detected in hair cells of $P j v k^{-1-}$ mice by in situ hybridization (Fig. $1 F, G$ ).

To genetically ablate Pjvk in hair cells, we generated a knock-in mouse line that expresses Cre from the endogenous otoferlin gene locus (Otof-Cre) that is selectively active in hair cells of the inner ear (Fig. 2A-D) (Yasunaga et al., 1999). To verify the Cre-mediated recombination pattern in inner ear sensory epithelia, we crossed the transgenic lines Otof-Cre and Ngn1-CreER ${ }^{\mathrm{T} 2}$ (Koundakjian et al., 2007) to Ai9 tdTomato Cre reporter mice (The Jackson Laboratory) (Madisen et al., 2010). In the early postnatal (P3) cochlea, Otof-Cremediated recombination was observed in most IHCs (base, $96 \pm$ 5\%) and some of the OHCs (base, $28 \pm 7 \%$ ) (Fig. 2E,F). By P30, all IHCs (base, $100 \pm 0 \%$ ) and most OHCs (base, $87 \pm 1 \%$ ) showed robust reporter activity (Fig. $2 E, F$ ). A few tdTomato-positive spiral ganglion neurons were occasionally observed (Fig. 2E, arrowhead). 
A

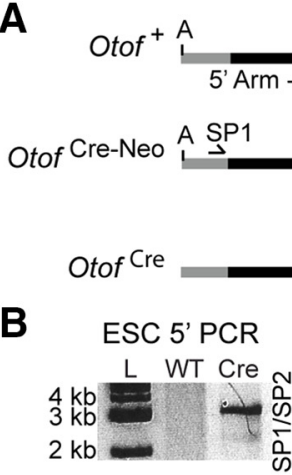

E

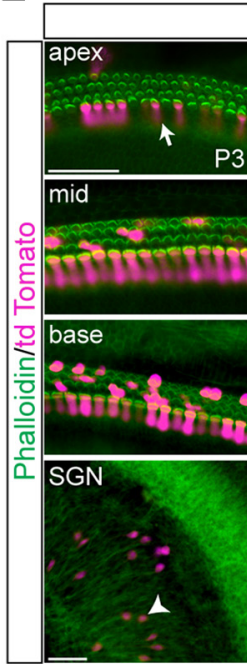

ATG A

IÇ1

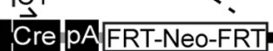

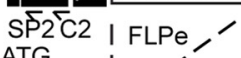
ATG Cre pAFRT A

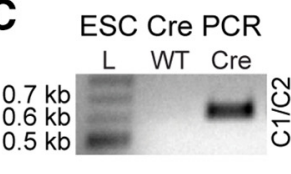

DESC 3' Southern

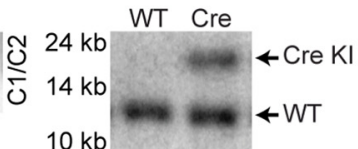

$10 \mathrm{~kb}$

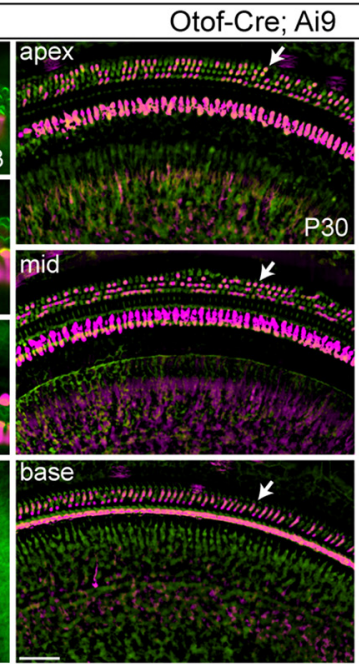

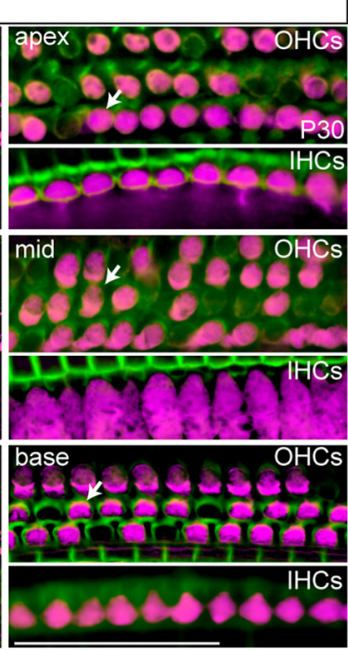

$\mathbf{F}$

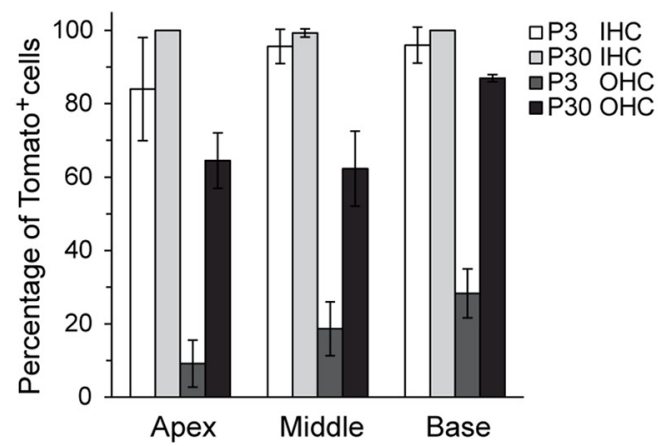

G

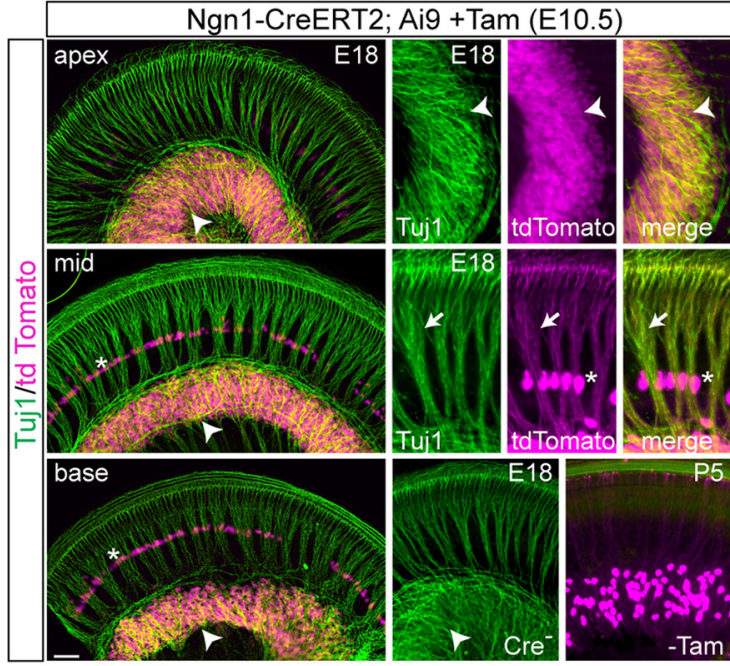

Figure 2. Generation and characterization of transgenic Cre mouse lines. $\boldsymbol{A}$, Schematic diagram of wild-type $(+)$ and $\mathrm{Cre}(\mathrm{Cre}-\mathrm{Neo}$, $\mathrm{Cre}$ ) alleles of the Otof gene. Thick black bars represent DNA segments used for constructing the targeting vector. Gray bars represent flanking genomic DNA. Relevant restriction sites (A, AflllI), Southern probe (thin black bar), and $P C R$ primers for screening the $5^{\prime}$ insertion (SP1, SP2) and Cre transgene $(C 1, C 2)$ are indicated. The Otof-Cre-Neo allele was converted to Otof-Cre by crossing to ACTB-FLPe (FLPe) mice to drive germline recombination of the FRT-Neo-FRT selection cassette. $\boldsymbol{B}$, PCR analysis of targeted ES cell clone confirming correct $5^{\prime}$ insertion. $\boldsymbol{C}, \mathrm{PCR}$ analysis of targeted ES cell clone confirming presence of the Cre transgene. D, Southern blot analysis of targeted ES cell clone confirming correct $3^{\prime}$ insertion. Genomic DNA from wild-type and targeted ES cells was digested with Afllll and hybridized with a 3' external probe. L, DNA ladder; WT, wild-type ES cell DNA; Cre, Cre-Neo targeted ES cell DNA. E, Representative images of the cochlea from Otof-Cre;Ai9 mice at P3 and P30 showing tdTomato expression (magenta) in hair cells (arrows). Sporadic Cre activity was detected in a few spiral ganglion neurons (bottom left). $\boldsymbol{F}$, Quantification of the percentage of tdTomato-positive IHCs and OHCs. G, Representative images of tdTomato expression in spiral ganglion neurons (SGNs) of Ngn 1-CreER ${ }^{\mathrm{T2}}$;Ai9 mice following 4-OHT induction at E10.5. No tdTomato expression was detected in Cre-negative mice (middle bottom). A small number of tdTomato-positive SGNs were detected at P5 in the absence of tamoxifen administration (bottom right). Values are mean \pm SEM. Scale bars: $\boldsymbol{E}, \boldsymbol{G}, 50 \mu \mathrm{m}$.

As reported previously, tamoxifen treatment at E10.5 caused strong tdTomato labeling of cochlear ganglion neurons in $\mathrm{Ngn1-CreER^{ \textrm {T } 2 }}$ transgenic mice (Fig. 2G) (Koundakjian et al., 2007; Coate et al., 2012). Sporadic expression of tdTomato in spiral ganglion neurons due to spontaneous Cre activity was also detected in the absence of tamoxifen, as noted previously (Fig. 2G, bottom right) (Coate et al., 2015).

Pejvakin in hair cells, but not in auditory neurons, is essential for hearing

To assess the effect of pejvakin deficiency in hair cells on hearing function, we recorded ABRs to broadband click stimuli in Pjvk $k^{\mathrm{fl} / \mathrm{fl}} \mathrm{O}$ tof-Cre ${ }^{+/-}, \mathrm{Pj}_{\mathrm{f}}^{\mathrm{fl} /+} \mathrm{Otof}-\mathrm{Cr} e^{+/-}$, and control $\left(\mathrm{Cre}^{-I^{-}}\right)$littermates. Wave I of the ABR represents the summed activity of the eighth cranial nerve; the subsequent peaks (II-IV) are the responses of neuronal populations in the auditory brainstem (Zheng et al., 1999). ABR waveforms were elicited in 1-month-old Pjvk ${ }^{\mathrm{fl} / \mathrm{fl}} \mathrm{O}$ tof-Cre ${ }^{+/-}$mice but at significantly higher sound-pressure levels compared with control mice (Fig. $3 A, B$ ). By 2 months, Pjvk $k^{\mathrm{fl} / \mathrm{fl}}$ Otof-Cre ${ }^{+/-}$mice ex- hibited severe hearing loss (hearing thresholds $80 \pm 3 \mathrm{~dB}$ SPL vs $40 \pm 4 \mathrm{~dB}$ SPL in control littermates). Analysis of auditory thresholds using pure tones between 4 and $32 \mathrm{kHz}$ revealed that $\mathrm{Pjv} \mathrm{k}^{\mathrm{fl} / \mathrm{fl}} \mathrm{Otof}$-Cre $\mathrm{C}^{+/-}$mice were affected across all frequencies with slightly more pronounced hearing loss at higher frequencies (Fig. 3C).

To verify the proposed role of pejvakin in regulating the activity of auditory pathway neurons (Delmaghani et al., 2006, 2015), we selectively inactivated the Pjvk gene in spiral ganglion neurons using Ngn1-CreER ${ }^{\mathrm{T} 2}$ mice. Relative to littermate controls, tamoxifen-treated $P j v k^{\mathrm{fl} / \mathrm{fl}} \mathrm{Ngn1-CreER^{ \textrm {T } 2 }}$ mice showed no significant difference in ABR thresholds (Fig. 3D,E) or wave amplitudes (wave I amplitude in P60 Pjvk ${ }^{\mathrm{fl} / \mathrm{fl}} \mathrm{Ngn1}-\mathrm{CreER}^{\mathrm{T} 2}$ mice for $12 \mathrm{kHz}$ stimulus: $0.7 \pm 0.1 \mu \mathrm{V}, n=10$; vs $0.9 \pm 0.1 \mu \mathrm{V}$, $n=8$; control littermates, $p=0.4, t$ test), indicating that both auditory sensitivity and the number of responsive spiral ganglion neurons were unaffected. In addition, absolute latencies of all four ABR waves and interpeak latencies between $A B R$ waves I and IV were not shifted (Fig. $3 F$ ), indicating normal conduction properties of the corresponding auditory neurons. Likewise, no 
A

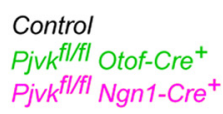

\begin{tabular}{ll|ll} 
I II III IV & $2 \mu \mathrm{V} \quad(\mathrm{dB})$
\end{tabular}
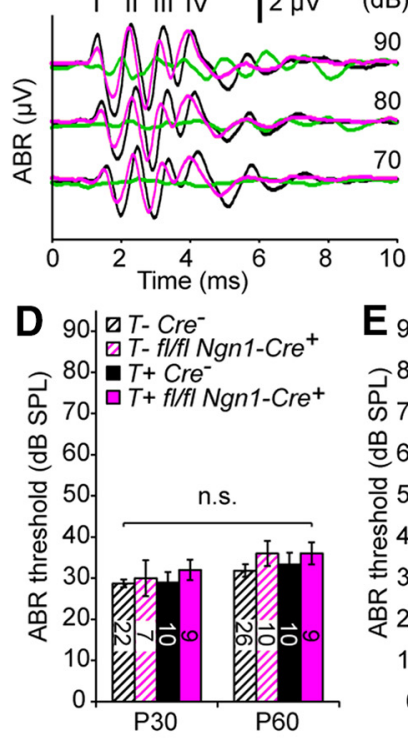

\section{G}

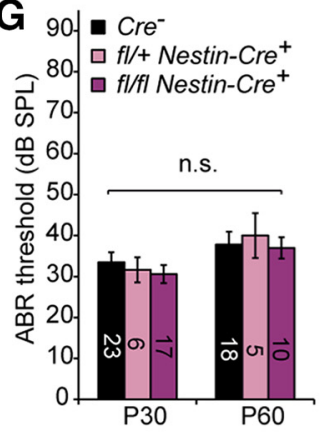

H
B $90|-|_{\text {Cre }}^{-2}$

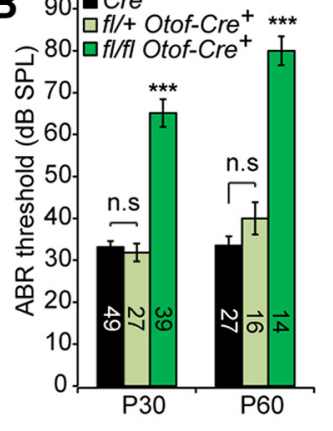

$E_{90}$
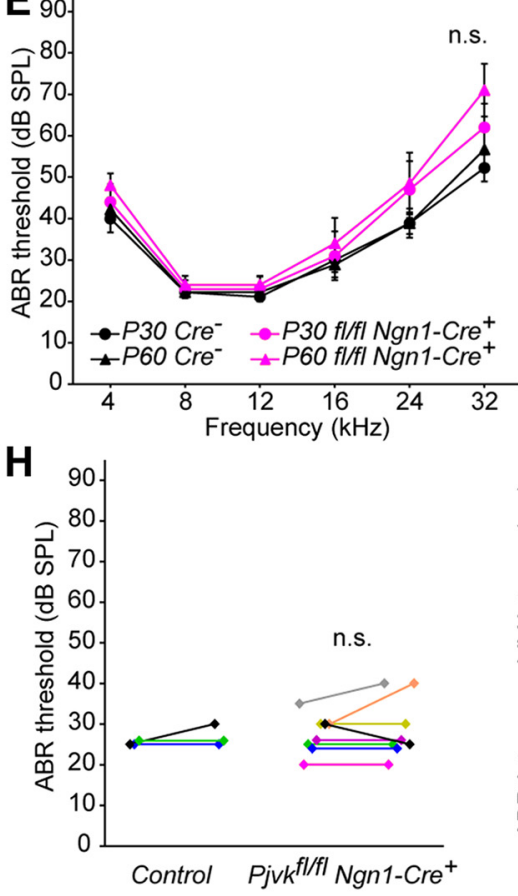

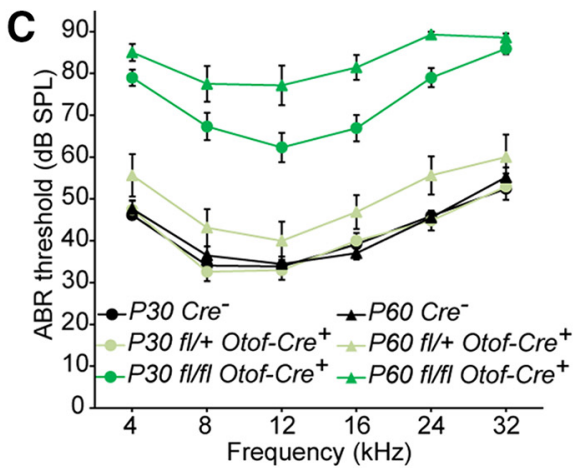

F

$\begin{aligned} & \text { aP30 Cre- } \\ 5 P 30 \text { fl/fi Ngn1-Cre } & +\end{aligned}$
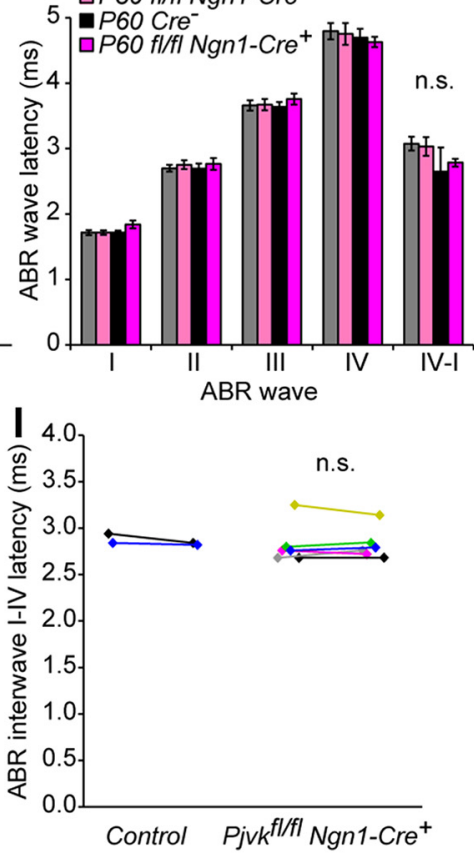

Figure 3. Analysis of auditory function in mice with conditional ablation of pejvakin in auditory hair cells and neurons. $A$, Representative ABR waveforms of Cre ${ }^{-/-}\left(\right.$Control), Pjvk ${ }^{f / f f}$ Otof-Cre ${ }^{+/-}$, and Pjvk ${ }^{f / f f} \mathrm{Ngn1-Cre}{ }^{+/-}$mice at P60. B, C, ABR thresholds to click (B) and pure tone (C) stimuli in Pjvk ${ }^{f / /+}$ and Pjvk ${ }^{f / f l}$ mice from the Otof-Cre colony at P30 and P60. The number of

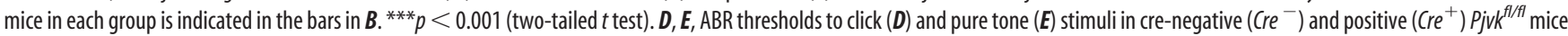
from the Ngn1-Cre colony at P30 and P60 (numbers of mice are indicated in the bars). The $T^{+}$groups were injected with tamoxifen at E10.5. No significant effect of tamoxifen, age, or genotype was detected (ANOVA, $F=1.5, F_{\text {crit }}=2.1, p=0.2$ ). $F$, Latencies of ABR waves I-IV evoked by $12 \mathrm{kHz}$ pure tone stimulus in Ngn 1-Cre colony mice. G, Click-ABR thresholds in mice from Nestin-Cre colony show no significant effect of age or genotype (ANOVA, $\left.F=1.2, F_{\text {crit }}=2.3, p=0.3\right)$. $\boldsymbol{H}, \boldsymbol{I}$, Analysis of $10 \mathrm{kHz}$ pure tone-evoked ABR thresholds $(\boldsymbol{H})$ and interwave latencies $(\boldsymbol{I})$ before and $2 \mathrm{~d}$ after noise exposure in (re-negative (Control) and -positive Pjvk ${ }^{f / f}$ mice from the Ngn 1-Cre colony at P30. No significant difference was detected in ABRs before and after exposure. $\boldsymbol{H}, p=0.5$ (paired $t$ test). $I, p=0.9$ (paired $t$ test).

significant effect of Nestin-Cre-mediated ablation of pejvakin in central neurons on the ABR was observed (Fig. 3G). We next verified the impact of sound stimulation on hearing in tamoxifen-treated $P j v k^{\mathrm{t} / \mathrm{l} l \mathrm{l}} \mathrm{Ngn1}$-CreER ${ }^{\mathrm{T} 2}$ mice following a recently described protocol for "controlled sound exposure" (1000 tone bursts at $10 \mathrm{kHz}$, at $105 \mathrm{~dB}$ SPL) (Delmaghani et al., 2015). Remarkably, no significant ABR threshold shifts were observed immediately after sound exposure and $2 \mathrm{~d}$ later (Fig. $3 H$ ). In addition, wave I-IV interpeak latencies remained unchanged (Fig. 3I). Together, the data suggest that pejvakin regulates hair cell function in a cell-autonomous manner but under the conditions tested herein does not affect the propagation of soundevoked action potentials in the auditory pathway.

$\mathrm{Pjvk}^{-1-}$ mice show progressive degeneration of hair cells Because Pjvk ${ }^{\mathrm{fl} / \mathrm{l}} \mathrm{Otof}$-Cre ${ }^{+/-}$mice may be mosaic for pejvakin inactivation in OHCs, we further characterized the auditory phe- notype of Pjvk ${ }^{-1-}$ mice. Measurement of click-evoked ABRs revealed that $P j v k^{-1-}$ mice were profoundly deaf at 1 month of age (hearing thresholds $86 \pm 3 \mathrm{~dB}$ SPL $[n=10]$ vs $36 \mathrm{~dB} \pm 2 \mathrm{~dB}$ SPL $[n=16]$ in heterozygous control littermates) (Fig. 4A). Analysis of responses to pure tones showed that the mutant mice were deaf across the entire frequency range (Fig. 4B). Based on our findings that pejvakin in hair cells is critical for hearing, we next examined whether it may regulate hair cell differentiation by analyzing the morphology of hair cells by immunohistochemistry and electron microscopy. To evaluate survival of hair cells, we stained cochlear whole mounts from Pjvk ${ }^{+/-}$and $\mathrm{Pjvk}^{-1-}$ mice with a myosin VIIa antibody. By fluorescence microscopy, both IHCs and OHCs appeared normal in P10 Pjvk ${ }^{-1-}$ mice (Fig. 4C). However, in older mice, OHCs started to degenerate in a basal to apical gradient along the cochlear duct, whereas IHCs remained largely intact (Fig. 4C). By P30, loss of only a few OHCs was observed in the mid-turn of the cochlea, whereas almost all 

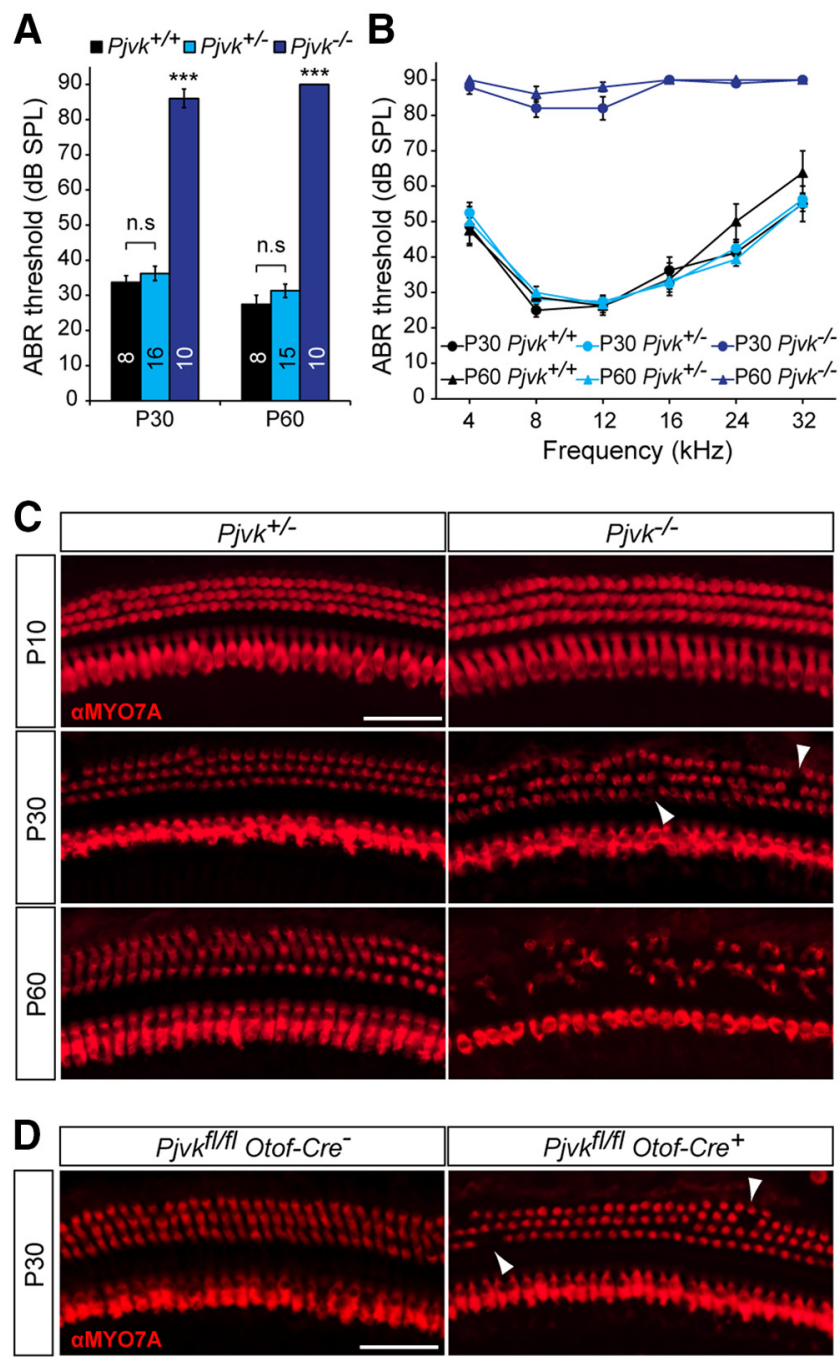
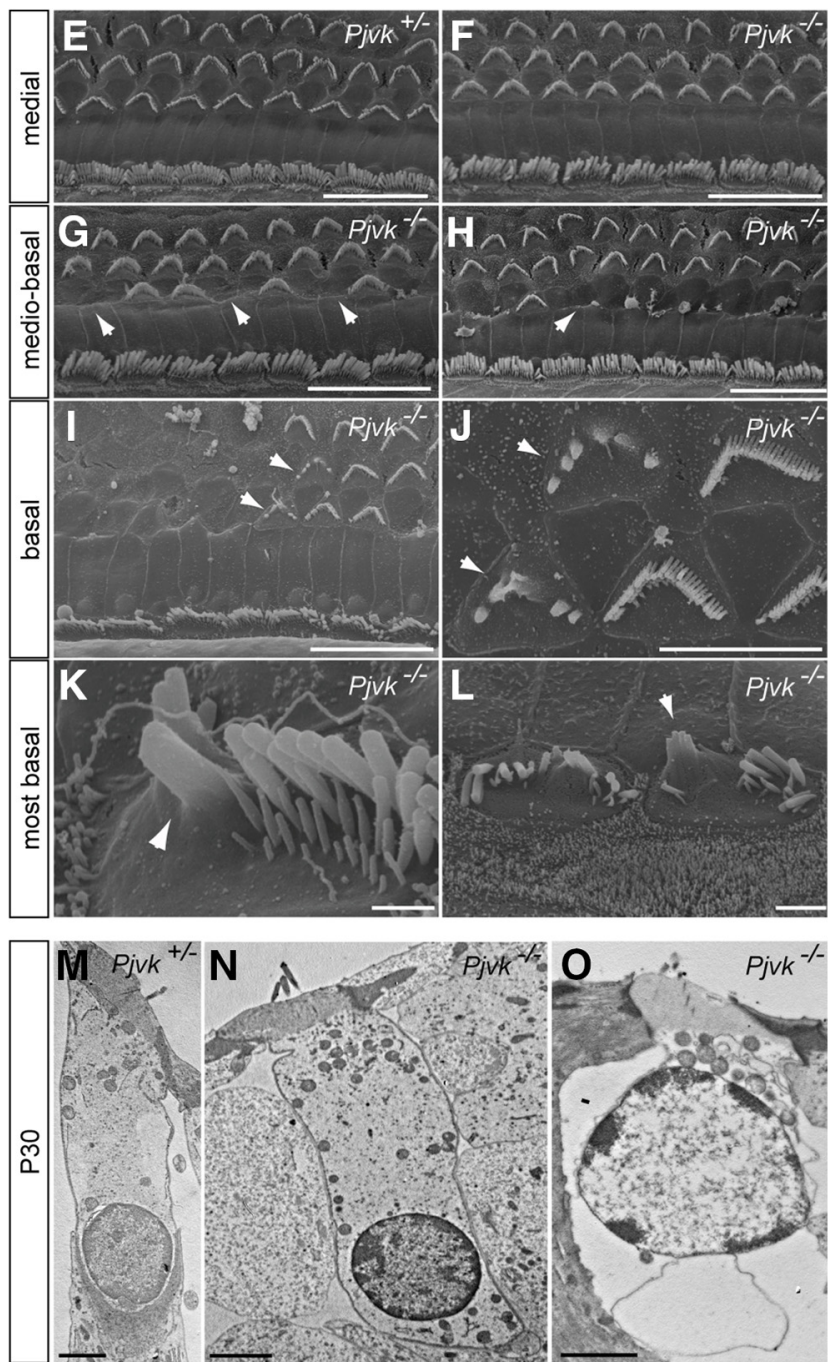

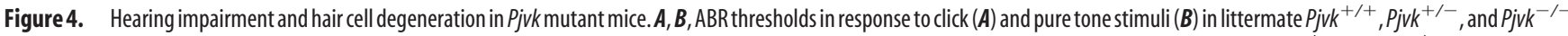
mice. Numbers of mice in each group are indicated in the bars (mean \pm SEM). ${ }^{* * *} p<0.005$ (two-tailed $t$ test). $\boldsymbol{C}, \boldsymbol{D}$, Cochlear whole mounts from littermate Pjvk ${ }^{+/-}$and Pjvk ${ }^{-/-}$mice $(\boldsymbol{C})$, as well as Pjvk ${ }^{f / f f}$ Otof-Cre ${ }^{-1-}$ and Pjvk ${ }^{f / f l}$ Otof-Cre ${ }^{+/+}$mice $(\boldsymbol{D})$, were immunostained against MYO7A to visualize hair cells. The ages of mice are indicated at the left margin. Sporadic missing $0 \mathrm{HCs}$ can first be seen in the mediobasal turn at $\mathrm{P} 30$ (arrows). E, SEM reveals normal organization of hair cells in the organ of Corti of Pjvk ${ }^{+/-}$mice at P30. $\boldsymbol{F}$-J, Base-to-apex gradient of hair cell degeneration in Pjvk ${ }^{-/-}$mice at P30. Bundle organization appears normal in the medial turn $(\boldsymbol{F})$. In the mediobasal turn $(\mathbf{G}, \boldsymbol{H})$, only a subset of bundles of the first row of $\mathrm{OHCs}$ is missing. In the basal turn, most $\mathrm{OHC}$ bundles are missing while IHCs persist $(\boldsymbol{I})$. The remaining $0 \mathrm{HCs}$ have fused stereocilia $(J) . \boldsymbol{K}, \boldsymbol{L}, \mathrm{In}$ the most basal "hook" region of the cochlea, IHC stereocilia fuse and degenerate. $\boldsymbol{M}$, TEM micrograph of a P3O Pjvk ${ }^{+/-} \mathrm{OHC}$ reveals normal morphology. $\mathbf{N}$, Example of a P3O Pjvk ${ }^{-/-} \mathrm{OHC}$ with no signs of degeneration. $\mathbf{O}$, Severe degenerative changes in another Pjvk ${ }^{-/-}$OHC. Note the swollen nucleus and lack of cytoplasm, indicative of a nonapoptotic cell death mechanism. The cuticular plate, hair bundle, and mitochondria are still present. Scale bars: $\mathbf{C}, \mathbf{D}, 10 \mu \mathrm{m} ; \boldsymbol{E}-\boldsymbol{I}, 15$ $\mu \mathrm{m} ; J, 6 \mu \mathrm{m} ; \boldsymbol{K}-\mathbf{0}, 2 \mu \mathrm{m}$.

OHCs were lost by P60 in the same region (Fig. 4C). A similar pattern of hair cell degeneration was present in Pjvk ${ }^{\mathrm{fl} / \mathrm{fl}}$ Otof$\mathrm{Cre}^{+1-}$ mice (Fig. 4D). The degeneration pattern observed by immunofluorescence was confirmed by SEM (Fig. $4 E-L$ ). Notably, at P30, the innermost row of OHCs (closest to the modiolus) showed significantly more loss relative to the middle and outermost rows in the mediobasal cochlear turn (Fig. 4G,H). In the basal turn, degeneration of OHCs was evident in all three rows (Fig. $4 I, J$ ), whereas IHCs were largely preserved except for the most basal region, in which IHCs showed fusion of stereocilia (Fig. $4 K, L$ ). TEM analysis revealed the presence of degenerating OHCs with swollen nuclei but no signs of nuclear condensation, indicative of necrosis (Fig. 4M-O). No caspase-3-positive hair cells were observed in $\mathrm{Pjvk}^{-1-}$ cochlea (data not shown), further suggesting that mechanisms of cell death other than apoptosis contribute to hair cell loss.

\section{Pejvakin localizes to the rootlets of stereocilia in} injectoporated hair cells

Although previous antibody studies found widespread expression for pejvakin in hair cells and neurons of the afferent auditory pathway (Delmaghani et al., 2006), Pjvk mRNA was specifically detected in hair cells but not in spiral ganglion neurons (Fig. 1F) (Schwander et al., 2007). A recent study, also by Delmaghani et al. (2015), has described a peroxisomal localization for pejvakin in hair cells. To verify the expression of pejvakin in the auditory system, we tested commercially available antibodies against pejvakin and custom-generated rabbit polyclonal antisera directed against different epitopes of mouse pejvakin. Three antibodies (see Experimental procedures) recognized pejvakin that was expressed as a GFPfusion protein in HeLa cells with high specificity (Fig. 5A, $B$ ). Pejvakin-GFP consistently exhibited a broad cytoplasmic dis- 

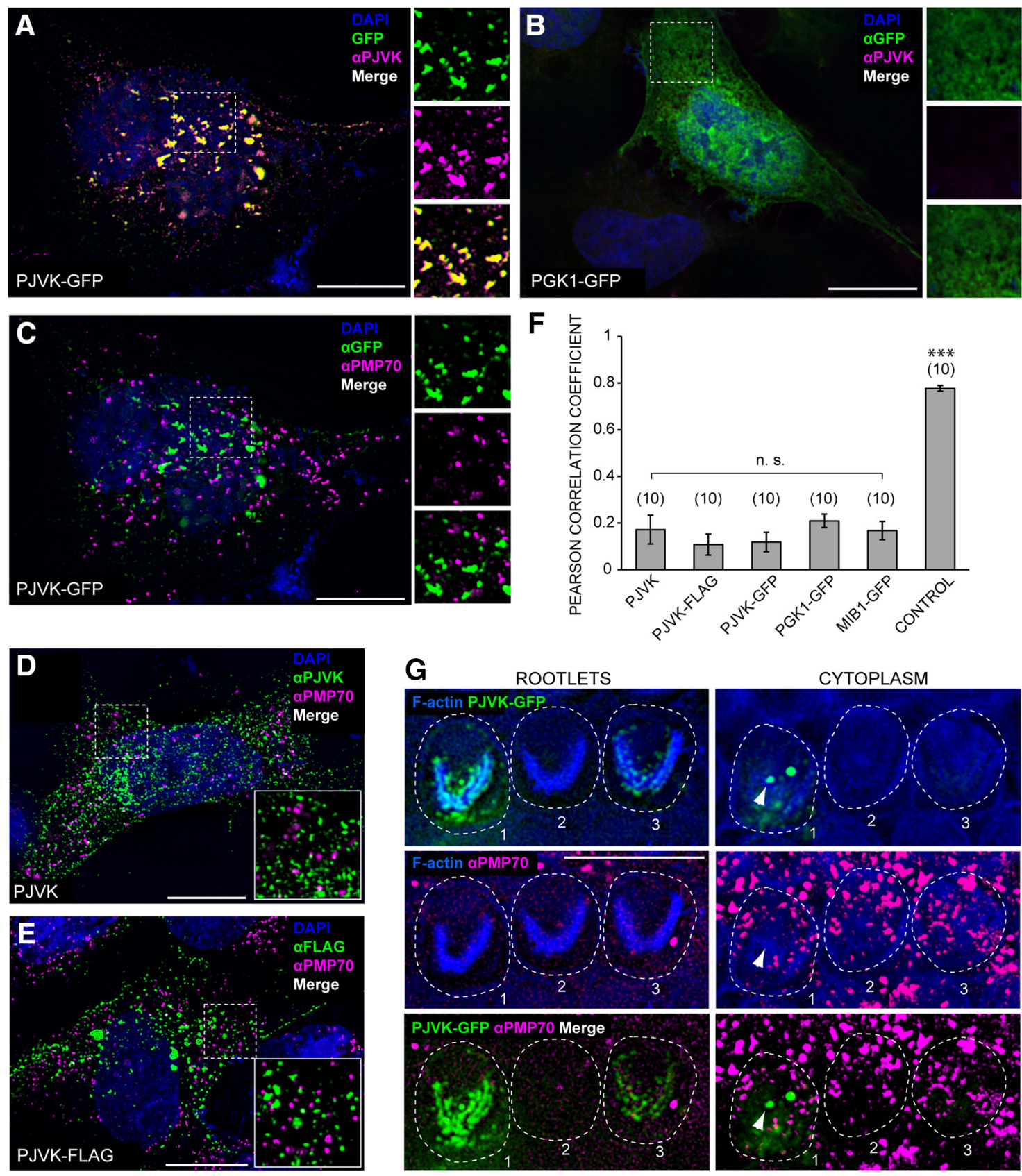

Figure 5. Pejvakin does not colocalize with peroxisomes. $\boldsymbol{A}-\boldsymbol{C}$, HeLa cells transfected with GFP-tagged pejvakin $(\boldsymbol{A}, \boldsymbol{C})$ and PGK1 (B) (green) were immunostained against PJVK $(\boldsymbol{A}, \boldsymbol{B})$ and peroxisomal marker PMP70 ( $\boldsymbol{C}$ (magenta). Anti-PJVK antibody recognized PJVK $(\boldsymbol{A})$, but not PGK1 (B). No colocalization was observed between PJVK and peroxisomes, detected with anti-PMP70 antibody (C).D, E, HeLa cells transfected with untagged (D) and FLAG-tagged (E) PJVK were immunostained against PMP70 (magenta) and PJVK (D) or FLAG (E) (green). No overlap was observed between PJVKand peroxisomes. $F$, The constructs indicated below the bars were expressed in HeLa cells and their colocalization with peroxisomes, labeled with anti-PMP70 antibody, was quantified with Pearson correlation method. Control group consisted of untransfected cells labeled with rabbit PMP70 antibody and two different secondary anti-rabbit antibodies. All Pearson correlation coefficients were smaller than 0.2 , except the positive control, indicating very low degree of correlation. The correlation of PJVK constructs with peroxisomes was not significantly different from the two negative controls, PGK1 and MIB1 (one-way ANOVA, $F=0.9, F_{\text {crit }}=2.6, p=0.4$ ). The number of cells used for quantification is indicated above the bars. Positive control showed significantly higher correlation than all constructs. ${ }^{* * *} p<0.005$ (two-tailed $t$ test). $G$, Cochlear explants from P4 wild-type mice were injectoporated with PJVK-GFP (green) and immunostained with anti-PMP70 antibody (magenta). The three presented OHCs are numbered: highly expressing (1), nontransfected (2), and weakly expressing (3). Peroxisomes were not detected at the rootlet level in the cuticular plate, at which the expression of PJVK is most pronounced (left column). In the hair cell body, some PJVK-GFP aggregates are visible in a highly expressing cell (1, arrowhead), but not in a weakly expressing one (3). PJVK-GFP aggregates do not colocalize with peroxisomes. Scale bars: All panels, $10 \mu \mathrm{m}$.

tribution and formed punctate aggregates in cells expressing high levels of the fusion protein (Fig. 5A). Likewise, anti-Flag and anti-pejvakin antibodies yielded a punctate cytoplasmic staining pattern in transfected HeLa cells expressing Flagtagged or untagged pejvakin, respectively (Fig. $5 D, E$ ). In contrast to previous studies (Delmaghani et al., 2015), we found no significant colocalization of GFP-, Flag-, or untagged pejvakin with the peroxisomal marker PMP70 in HeLa cells (Fig. $5 C-E$ ). A quantitative analysis revealed no significant difference between the degree of correlation of PMP70 signal with pejvakin and with two unrelated proteins, PGK1 and MIB1, which served as negative controls (Fig. 5F). 

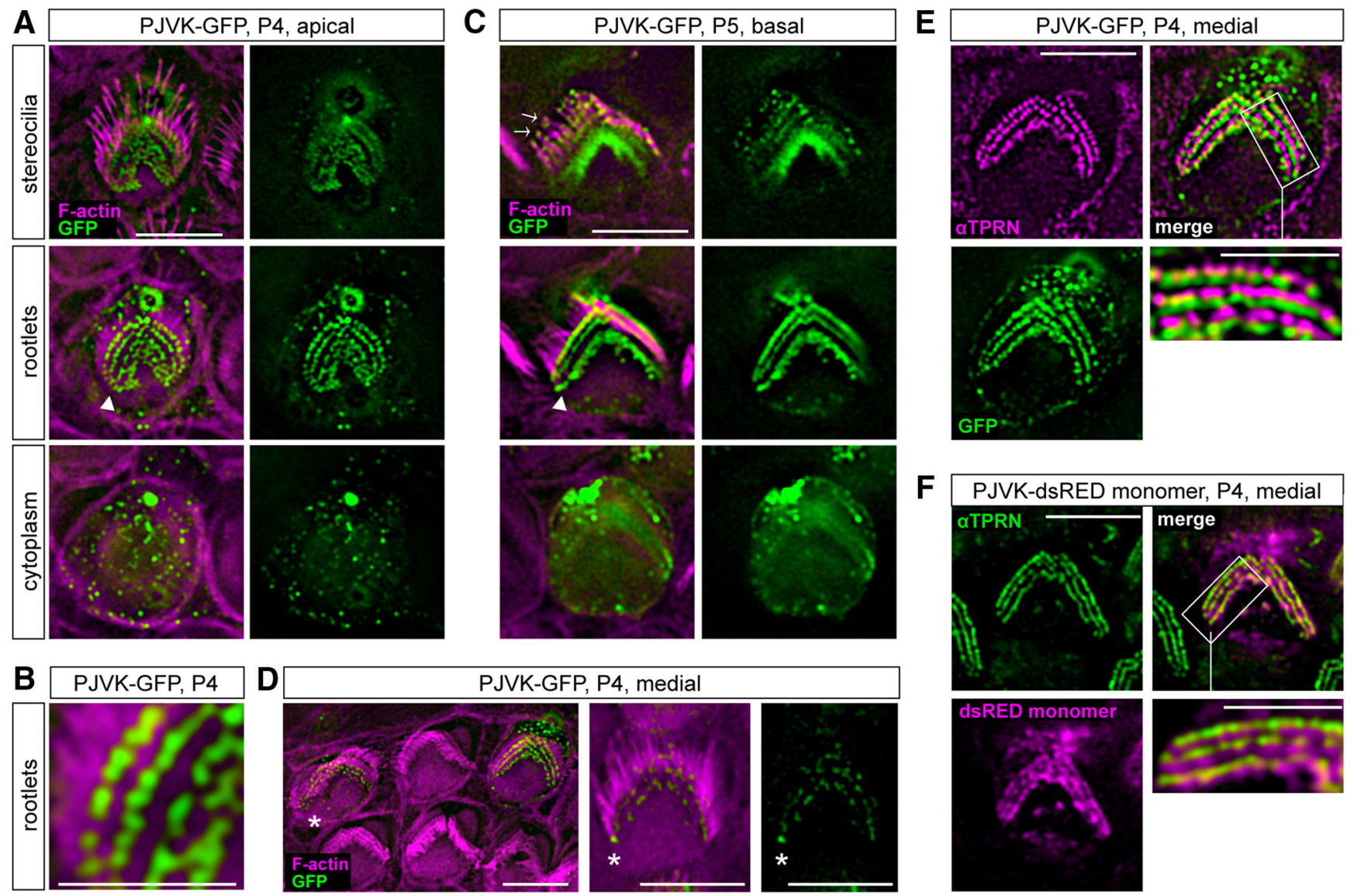

\section{F PJVK-dsRED monomer, P4, medial}
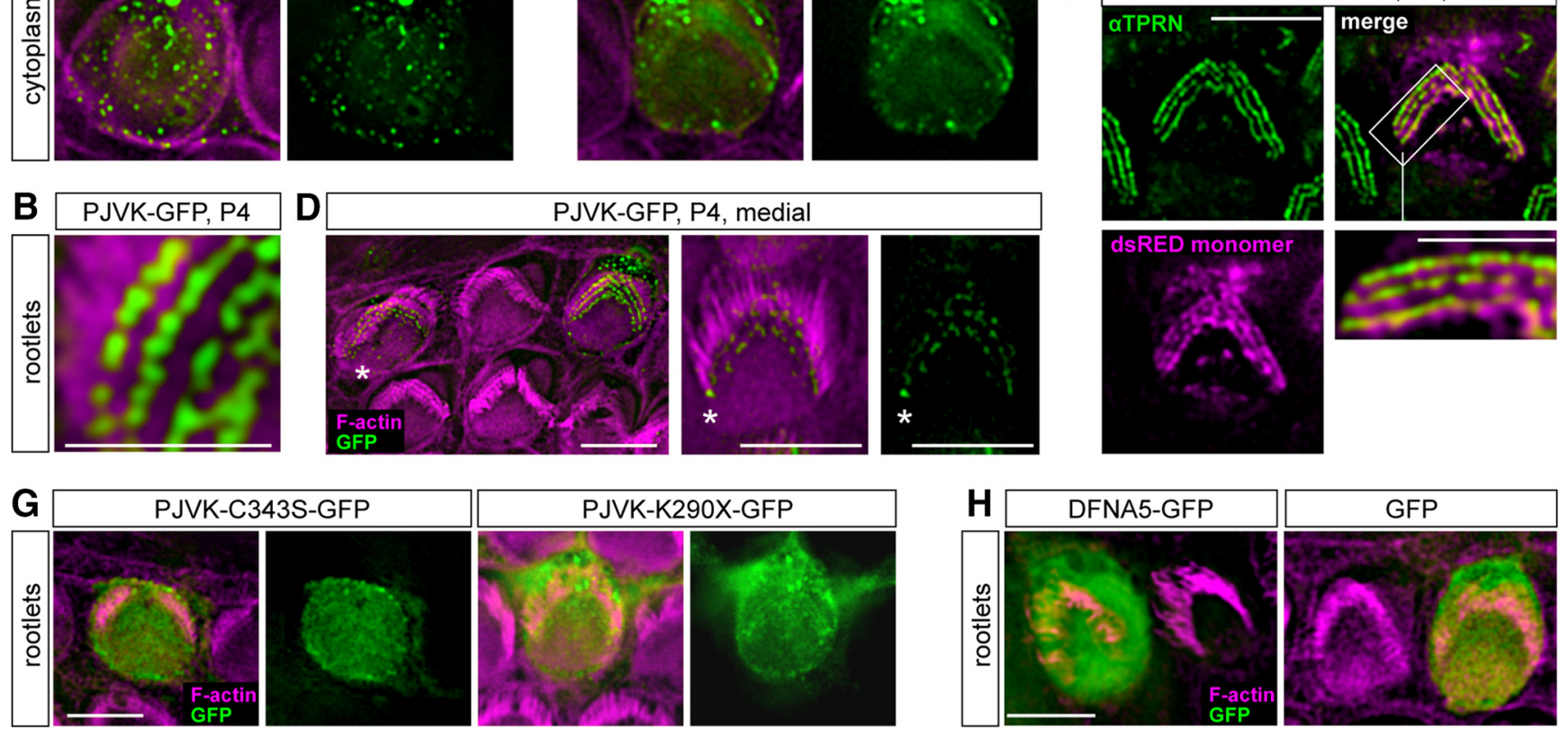

Figure 6. PJVK localizes to the base of stereocilia in auditory hair cells. $\boldsymbol{A}-\boldsymbol{F}$, Organs of Corti dissected from early postnatal (57BL/6J mice were injectoporated with PJVK-GFP (A-E) and PJVK-dsRED monomer $(\boldsymbol{F})$ plasmids. $\boldsymbol{A}$, In apical OHCS, PJVK-GFP localized to the rootlet region at the base of stereocilia (arrowhead). $\boldsymbol{B}$, High-magnification images of the $0 \mathrm{HC}$ depicted in $\boldsymbol{A}$ reveal rootlet localization of PJVK-GFP. C, Localization of PJVK-GFP at rootlets in basal OHCS (arrowhead). Weak GFP signals were also detected near stereociliary tips (arrows). D, Cytoplasmic aggregates of overexpressed PJVK-GFP are not visible in low-expressing OHCs (asterisks). $\boldsymbol{E}, \boldsymbol{F}$, Immunostaining of injectoporated explants against TPRN reveals that both PJVK-GFP (E) and PJVK-dsRED monomer $(\boldsymbol{F})$ localize to the base of stereocilia, immediately below the taper region. $\mathbf{G}, 0 \mathrm{HCs}$ from $[57 \mathrm{BL} / 6 \mathrm{~J}$ mice were injectoporated to express the indicated mutant PJVK proteins. In contrast to wild-type PJVK, the mutant PJVK proteins were no longer localized at rootlets. $\boldsymbol{H}, \mathrm{OHCs}$ were injectoporated to express GFP-tagged DFNA5 or GFP alone. GFP fluorescence was visible only in the cytoplasm. Scale bars: $\boldsymbol{A}, \boldsymbol{C}, \boldsymbol{D}, \boldsymbol{E}-\boldsymbol{G}, \boldsymbol{H}, 5 \mu \mathrm{m} ; \boldsymbol{B}$, and $\boldsymbol{E}, \boldsymbol{F}$, insets, $2.5 \mu \mathrm{m}$.

Likely because of epitope masking and low expression levels of pejvakin, commercially available and our custom rabbit polyclonal antibodies failed to detect any differences between cochlear tissues from Pjvk ${ }^{-1-}$ and wild-type mice. To examine the subcellular distribution of pejvakin, we expressed cDNAs encoding various fragments of pejvakin as GFP fusions in hair cells by injectoporation of cochlear explants from P4 wild-type mice, following a recently described protocol (Xiong et al., 2014). After 1 DIV, cochlear explants were fixed and stained with phalloidin to visualize F-actin in stereocilia. Strikingly, we found that pejvakin-GFP accumulated in a dot-like pattern at the base of stereocilia (Fig. 6A). Higher-magnification views revealed the presence of the fusion protein at the base of stereocilia and their extensions, the rootlets (Fig. 6B). When expressed in hair cells closer to the cochlear base at P5 (+1 DIV), pejvakin-GFP was primarily localized at rootlets, but occasional fluorescence puncta were also visualized near the tips of stereocilia (Fig. 6C). In cells expressing high levels of pejvakin-GFP, the fusion protein formed aggregates in the cytoplasm of hair cells (Figs. 5G, 6A,C), whereas cells with low expression levels displayed only the rootlet pattern (Fig. 6D). Importantly, there was little or no colocalization between cytoplasmic pejvakin-GFP aggregates and the peroxisomal marker PMP70 (Fig. 5G). Next, we injectoporated P4 cochlear explants with pejvakin-GFP and stained with an antibody to taperin to label the taper region in stereocilia (Rehman et al., 2010). Pejvakin-GFP localized to a region immediately below the stereocilia taper (Fig. 6E). Because some GFP fusions can induce aggregation or inappropriate localization of appended proteins (Rappoport and Simon, 2008), we next analyzed the cellular distribution of pejvakin tagged with dsRed monomer. This monomeric red fluorescent protein belongs to a different group of fluorescent proteins that share no sequence homology 
with GFP, and it has been engineered to eliminate the tendency of the original dsRed to form tetramers (Campbell et al., 2002). Pejvakin-dsRed monomer was observed as discrete foci at the base of stereocilia, similar in appearance to the pattern observed for the GFP-tagged protein (Fig. $6 F$ ). Next, we introduced the deafnesscausing mutations p.C343S (Mujtaba et al., 2012) and p.K290X (Schwander et al., 2007) into the cDNA encoding murine pejvakin and expressed the proteins by injectoporation in cochlear hair cells. Pejvakin-C343S and pejvakin-K290X were evenly distributed throughout the cytoplasm, and the rootlet pattern was abrogated (Fig. 6G). Likewise, diffuse cytoplasmic fluorescence, but no rootlet pattern, was observed in hair cells expressing GFP-tagged DFNA5, the closest homolog of pejvakin, or GFP alone (Fig. $6 H)$. We conclude that exogenous pejvakin accumulates at actin-rich stereocilia rootlets.

Although some of the anti-PJVK antibodies specifically detected PJVK-GFP in transfected HeLa cells (Fig. 5A), as well as its cytoplasmic aggregates in injectoporated hair cells (data not shown), they failed to detect PJVK-GFP at rootlets, despite antigen retrieval and the apparent presence of the fusion protein at this location as indicated by natural GFP fluorescence. This result suggests that pejvakin may be incorporated into a tight rootlet structure that is inaccessible to antibodies. It also emphasizes the advantages of injectoporation techniques (Xiong et al., 2014) in determining subcellular localization of novel proteins.

\section{$\mathrm{C}$ terminus of pejvakin mediates rootlet localization and interacts with TRIOBP}

Given the localization of pejvakin to the base of stereocilia, we next asked whether it might interact with TRIOBP, the only known component of rootlets, with essential functions in their assembly (Kitajiri et al., 2010). Injectoporation of OHCs from P4 wild-type mice with GFP-tagged TRIOBP1 yielded a dot-like pattern at the base of stereocilia, confirming that this technique is well suited to evaluate localization of rootlet proteins (Fig. 7A). Coexpression of GFP-TRIOBP1 and PJVK-dsRED monomer in $\mathrm{OHCs}$ and labeling with anti-TPRN antibody showed that both fusion proteins colocalized just below the taper region (Fig. $7 B$ ). Analysis of sequential focal planes revealed that TRIOBP1 and PJVK constructs are targeted to the same $\sim 1$ - $\mu$ m-thick compartment at stereocilia rootlets (Fig. $7 C$ ).

We next asked whether the C-terminal domain or N-terminal GSDM domain of pejvakin may colocalize with TRIOBP1 in HeLa cells. Consistent with previous reports (Bradshaw et al., 2014), GFPtagged TRIOBP1 by itself formed large puncta of aggregated protein (Fig. 8A). These aggregates were also formed by HA-tagged TRIOBP1, although they had a ring-like appearance, which is likely due to the inability of the anti-HA antibody to penetrate the tight
B

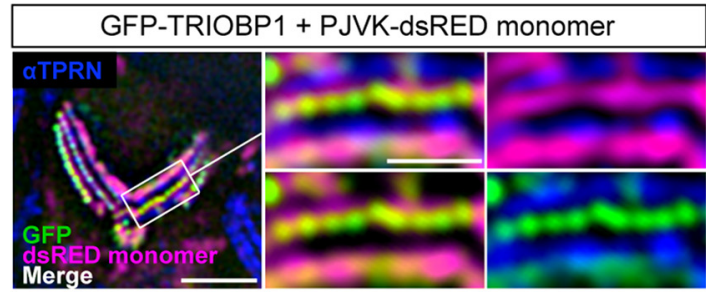

Merge
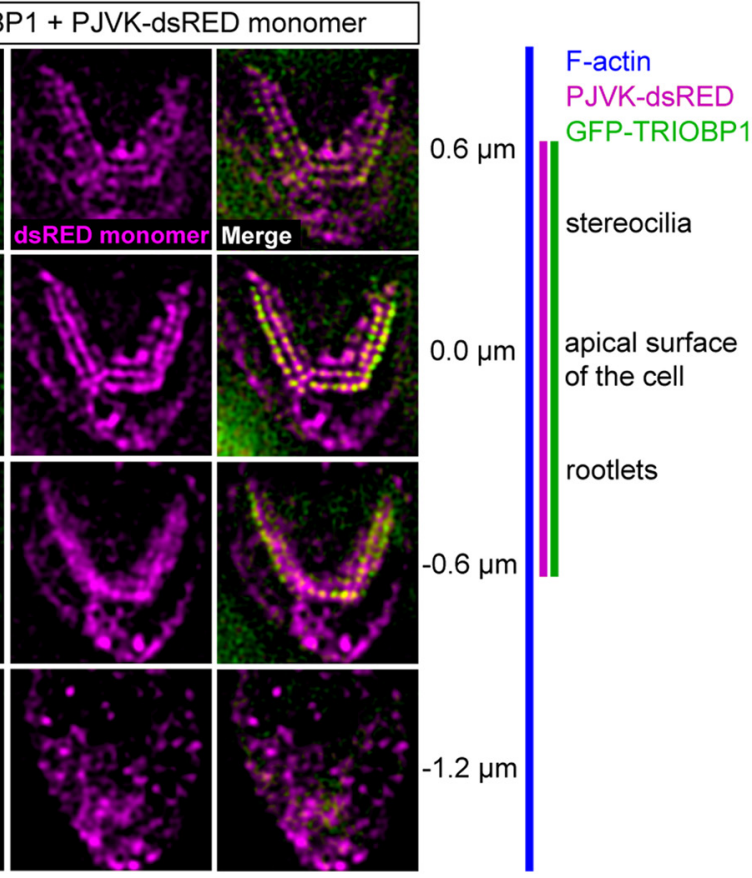

$0.0 \mu \mathrm{m}$

apical surface

of the cell

rootlets

$-0.6 \mu \mathrm{m}$

$-1.2 \mu \mathrm{m}$

Figure 7. Colocalization of TRIOBP1 and PJVK at stereociliary rootlets. A-C, GFP-TRIOBP1 (green) alone (A) or together with PJVK-dsRED monomer (magenta) $(\boldsymbol{B}, \boldsymbol{C})$ were injectoporated into P4 organs of Corti. Cells were stained for taperin (TPRN, blue). $A$ Expression of GFP-TRIOBP1 in a dot-like pattern. $\boldsymbol{B}$, Extensive colocalization of GFP-TRIOBP1 and PJVK-dsRED in a region just below the stereocilia taper. $C$, Analysis of vertical distribution of GFP-TRIOBP1 and PJVK-dsRED monomer on sequential focal planes. Scale bars: $\boldsymbol{A}-\boldsymbol{C}, 2.5 \mu \mathrm{m} ; \boldsymbol{B}$, Inset, $1 \mu \mathrm{m}$.

aggregate core (Fig. 8A). The cytoplasmic distribution of GFP-PJVK C-terminal domain and PGK1, which served as a negative control, was uniform (Fig. 8A). However, upon coexpression with TRIOBP1, GFP-PJVK C-terminal domain formed large cytoplasmic puncta that perfectly colocalized with TRIOBP1-HA (Fig. 8B). By contrast, neither PJVK GSDM domain nor PGK1 colocalized with TRIOBP1 aggregates (Fig. $8 B$ ). We next repeated the colocalization assays in HeLa cells with constructs containing different domains of TRIOBP1 and PJVK and titrated the concentrations of each plasmid. The mid-to-coiled-coil region (midCC) and the coiled-coil (CC) domain of TRIOBP1 formed aggregates, even at low plasmid concentrations ( $1 / 10$ dilution, $0.05 \mu \mathrm{g} /$ well), that colocalized with the C-terminal domain of PJVK, but not with PABPC1, which served as a negative control (Fig. 8C). Colocalization of TRIOBP1-CC and PJVK C-terminal domain was also detected at the cell cortex (Fig. $8 C$, right, arrowhead). Thus, our data suggest that the two proteins are appropriately localized in heterologous cell lines and hair cells to act in a common subcellular compartment.

While colocalization of PJVK and TRIOBP1 at the rootlets may result from independent targeting of both proteins to the same area, the apparent TRIOBP1-induced aggregation of PJVK C-terminal domain strongly indicates that these proteins form a complex. To test this possibility, we performed coimmunoprecipitation assays in HEK293T cells 
A

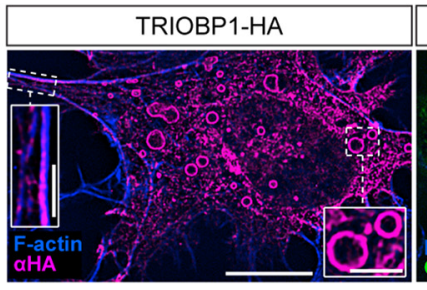

B

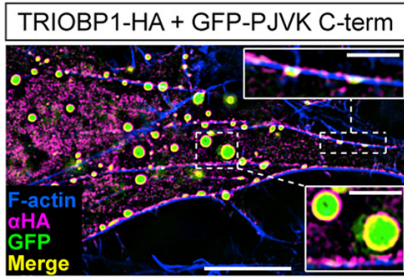

Merge
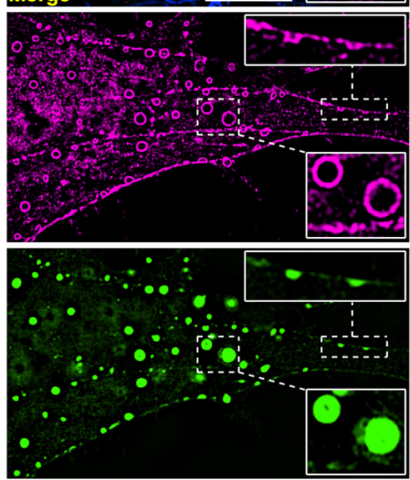

C
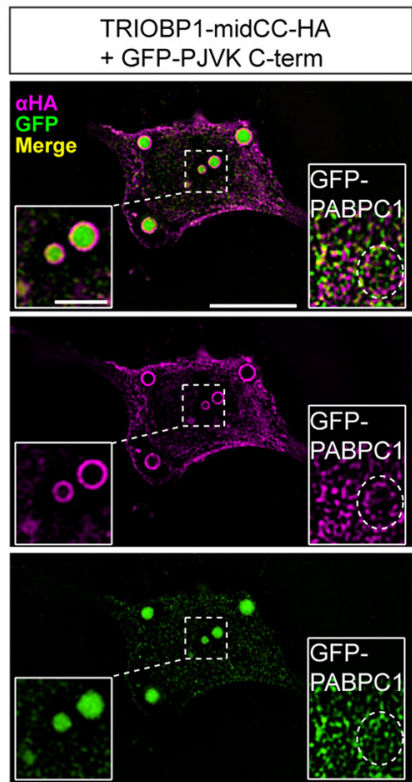
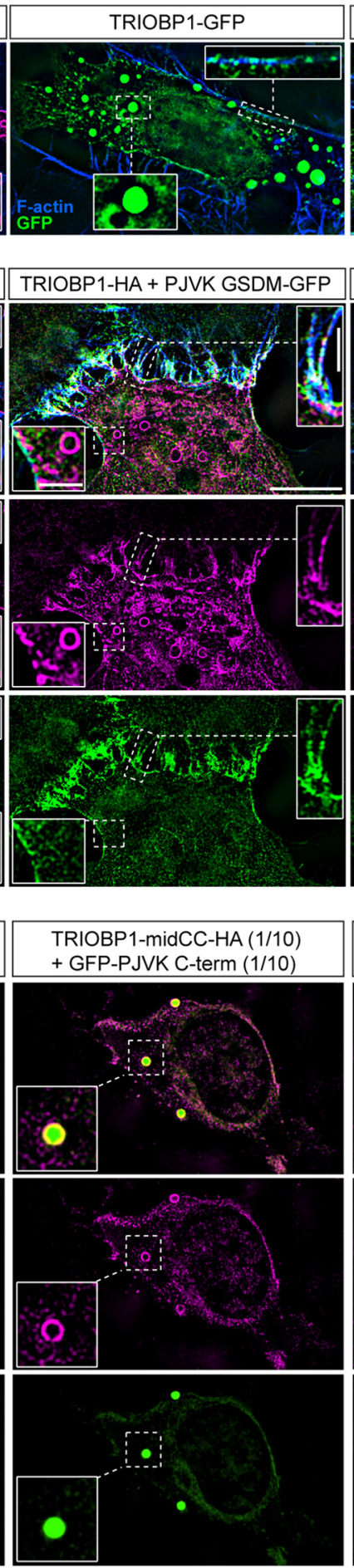
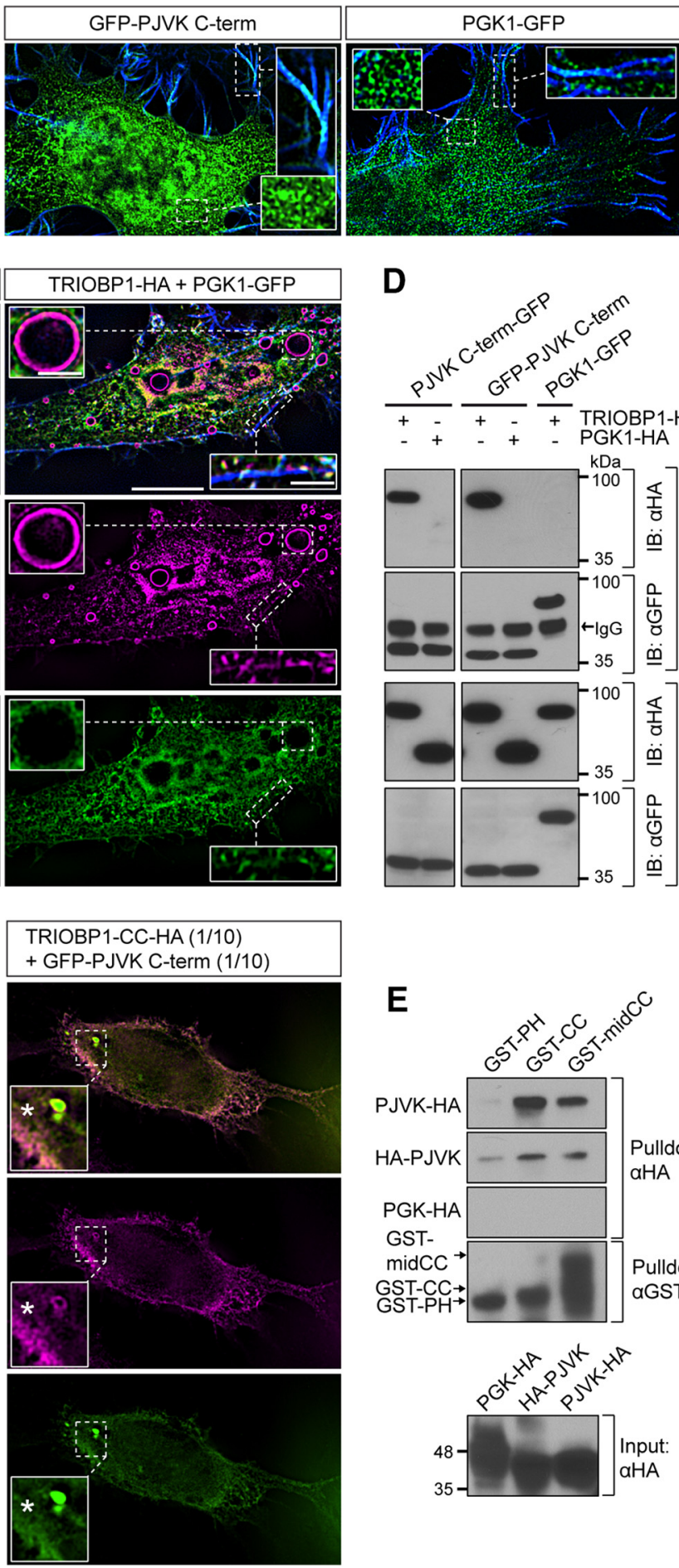
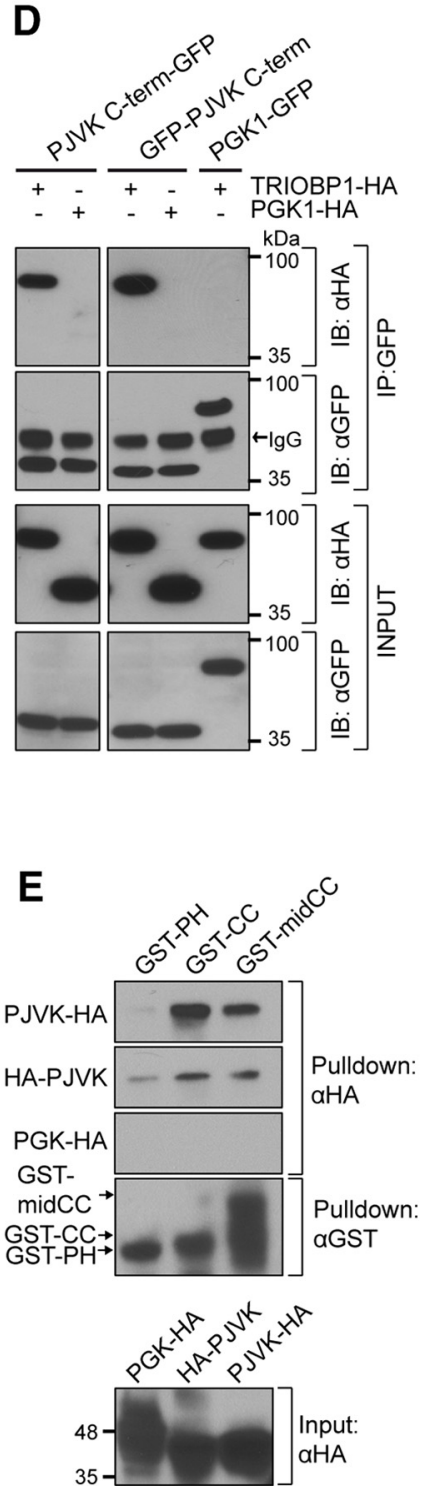

Figure 8. Interactions between TRIOBP1 and PJVK C-terminal domain. $\boldsymbol{A}$, HeLa cells were transfected with constructs indicated on top of each panel. The distribution of overexpressed proteins was visualized with anti-HA antibody (magenta), natural GFP fluorescence (green), and phalloidin (F-actin, blue). TRIOBP1 forms cytoplasmic aggregates whose cores are so dense that they cannot be penetrated by antibodies, giving TRIOBP1-HA aggregates a ring-like appearance. The ring-like appearance is not visible for TRIOBP1-GFP aggregates that can be visualized without antibody. PJVK C-term is uniformly distributed in the cytoplasm, but it also shows affinity to the actin-based filopodial cores. No preferential association with F-actin or aggregate formation was observed for PGK1-GFP, which served as a negative control. B, HeLa cells were cotransfected with constructs indicated on top of each panel and analyzed for protein localization $1 \mathrm{~d}$ after transfection. Magenta represents HA-tagged TRIOBP1. Green represents GFP-tagged domains of PJVK and PGK1-GFP. F-actin was labeled with phalloidin (blue). The C-terminal domain, but not the gasdermin (GSDM) domain, of PJVK or PGK1, colocalized with TRIOBP1 aggregates. C, HeLa cells were cotransfected with expression vectors for GFP-tagged PJVK C-terminal domain and either the mid-to-coiled-coil region (midCC) or the coiled-coil domain (CC) of TRIOBP1 with an HA-epitope tag. TRIOBP aggregate formation occurred in cells transfected with either construct at standard or 10-fold lower plasmid concentrations (1/10;0.05 $\mu \mathrm{g} /$ well). The C-terminal domain of PJVK (left insets), but not PABPC1 (right inset, left), colocalized with TRIOBP in aggregates and at the cell cortex (asterisk). D, HEK293T cells were transfected with the constructs indicated on top of each panel. Immunoprecipitations were performed with GFP antibody followed by Western blotting with GFP and HA antibodies. $\boldsymbol{E}$, In vitro-translated PJVK-HA, HA-PJVK, and HA-PGK1 proteins were incubated with GST fusion proteins of TRIOBP1 PH domain (GST-PH), coiled-coil domain (GST-CC), and mid-to-coiled-coil region (GST-midCC) bound to GST-beads, and the pulled-down proteins were analyzed by immunoblot with anti-HA and anti-GST antibodies. Scale bars: $A-C, 10 \mu \mathrm{m} ; \mathrm{Insets,} 2.5 \mu \mathrm{m}$. 
cotransfected with GFP and HA-tagged constructs. Although full-length pejvakin coprecipitated TRIOBP1, it also showed nonspecific binding to other proteins in the CoIP assays and its possible interaction with TRIOBP1 could not be reliably verified (data not shown). However, an indication of the binding specificity was observed in coprecipitations with differently GFP-tagged proteins. TRIOBP1HA specifically coprecipitated with the C-terminal domain of pejvakin tagged with GFP at either end, but not with PGK1-GFP (Fig. 8D). To further verify the interactions between PJVK and TRIOBP1, we performed pulldown assays using GST-TRIOBP1 fusion proteins, containing the pleckstrin homology $(\mathrm{PH})$ domain, mid-to-coiled-coil (mid$\mathrm{CC}$ ) region, or coiled-coil (CC) domain of TRIOBP1 immobilized on glutathioneSepharose beads. GST-TRIOBP1 fusion proteins were incubated with in vitro translated HA-tagged full-length PJVK and PGK1 constructs. PJVK bound to the CC domain but not the PH domain of TRIOBP1, whereas no interactions were observed for PGK1 (Fig. 8E). Together, these findings suggest that PJVK associates with the CC-domain of TRIOBP1 via its C-terminal domain. The longest isoform of TRIOBP, TRIOBP5, includes TRIOBP1 in its C-terminal domain (Kitajiri et al., 2010). Hence, our finding that the C-terminal pejvakin domain interacts with TRIOBP1 also suggests an interaction between PJVK and TRIOBP5.

We next asked whether the C-terminal domain of pejvakin may be important for rootlet localization, by injectoporating OHCs to express the GFP-tagged N-terminal GSDM domain of pejvakin. We found that the GSDM domain of pejvakin was distributed along the length of stere-

ocilia (Fig. 9A). When expressed in HeLa cells, the GSDM domain preferentially colocalized with F-actin in the cell cortex and in filopodial cores (Fig. 9B). This localization pattern did not significantly differ from the one obtained in the presence of TRIOBP1 and suggests that colocalization of the GSDM domain and TRIOBP1 in filopodia (Fig. 8B), but not in cytoplasmic aggregates, results from independent targeting of these proteins to actin-rich structures. Together, these data suggest that the GSDM domain of pejvakin has affinity to F-actin and is targeted to stereocilia, whereas the $\mathrm{C}$ terminus anchors pejvakin at the stereocilia base, possibly via its interaction with TRIOBP1 and/or TRIOBP5.

\section{Pjvk ${ }^{-/-}$hair cells develop normal stereocilia rootlets}

Previous studies have shown that mice deficient in the actinbundling proteins TRIOBP-4/5 develop hair bundles that lack stereocilia rootlets (Kitajiri et al., 2010). We therefore wondered whether pejvakin and TRIOBP-4/5 might cooperate to regulate rootlet assembly. However, when we colabeled cochlear tissues with a TrioBP4/5 antibody and phalloidin, we found that TRIOBP-4 and -5 were targeted normally to rootlets of hair cells in both Pjvk ${ }^{+1-}$ and Pjvk $k^{-1-}$ mice at P7 (Fig. 10A). Similarly, the distribution of taperin and radixin, two hair-bundle proteins that localize to the stereocilia basal taper, was not affected by disruption of pejvakin activity (Fig. 10A).

Given the rootlet localization of pejvakin, we next examined rootlet ultrastructure in OHCs from Pjvk ${ }^{+/-}$and Pjvk ${ }^{-/-}$mice by TEM. OHCs typically have three rows of stereocilia, all of which form rootlets (Furness et al., 2008). Horizontal sections through stereocilia insertions into the cuticular plate revealed that each rootlet consists of a central core surrounded by a peripheral dense ring (Fig. 10B-E). At P18, no apparent differences in the morphology of rootles were observed between genotypes, and the width of the core actin bundles was comparable (Fig. $10 D, E)$. Occasionally, additional dense material was noted near the rootlet central core, indicating that rootlets may splay within stereocilia (Fig. $10 F-K$, asterisks). These ultrastructural features of the rootlet were present in both $P j v k^{+/-}$and $P j v k^{-/-}$mice. Even at P30, in longitudinal sections through OHCs (Fig. 10 L, M) and IHCs (Fig. $10 N-P$ ), rootlet structures appeared normal in size and were surrounded by a meshwork of dense material giving the appearance of a lighter zone around the filaments (Furness et al., 2008). Occasionally, dense material was observed further up the shaft (Fig. 10P), which was displaced to the periphery of the 
A
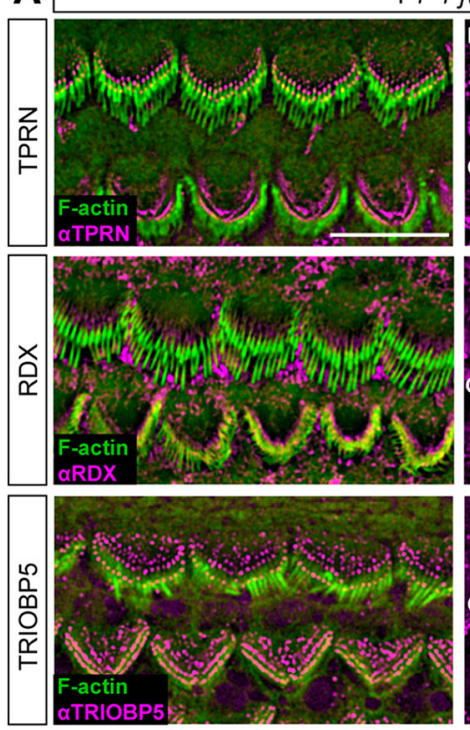

7 Pjvk $^{+/-}$
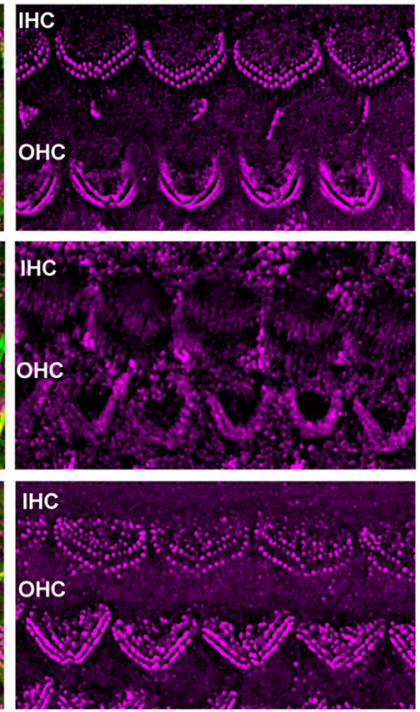

P7 Pjvk $^{\text {/- }}$
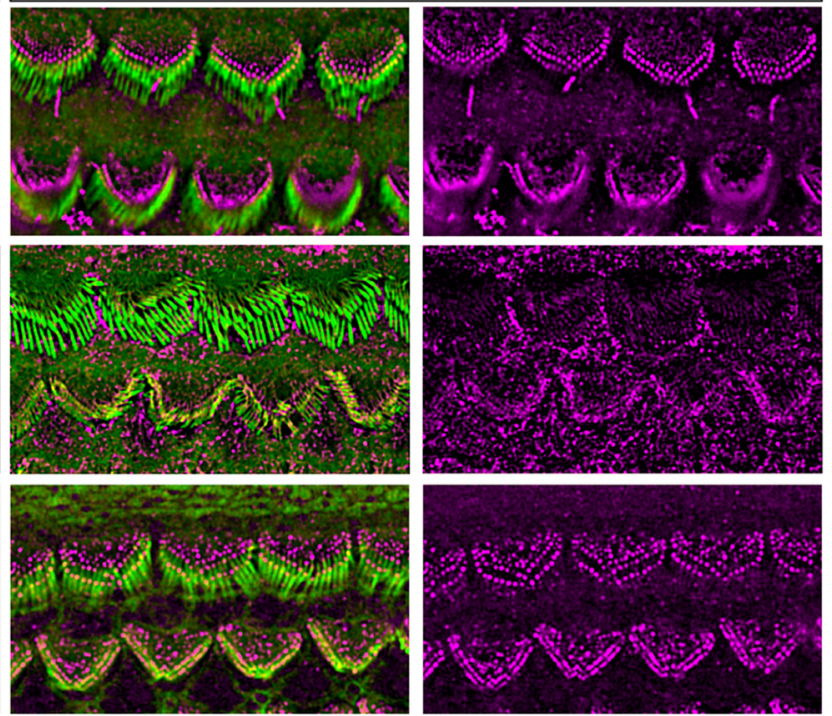
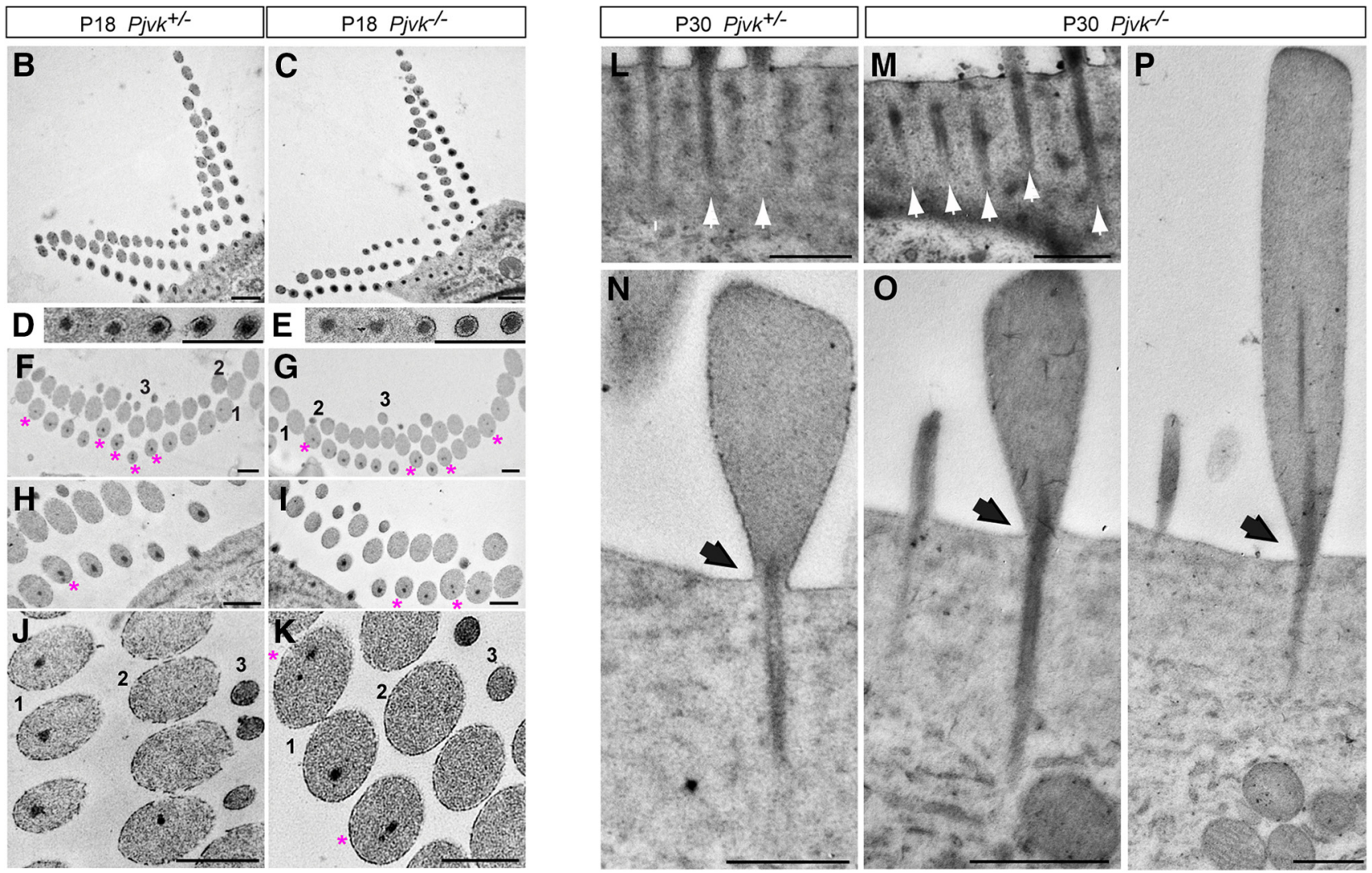

Figure 10. Normal ultrastructure of rootlets and distribution of stereociliary base components in Pjvk ${ }^{-/-}$hair cells. $A_{\text {, Cochlear whole mounts from P7 Pjvk }}^{+/-}$and Pjvk ${ }^{-/-}$littermate mice were stained with phalloidin (green) to visualize $F$-actin and with antibodies against rootlet and stereociliary proteins indicated on the left (magenta). The distribution of TPRN, RDX, and TRIOBP5 appears normal in P7 Pjvk ${ }^{-1-}$ mice. $\boldsymbol{B}-\boldsymbol{K}$, TEM of axial sections through the stereocilia of $\mathrm{OHCS}(\boldsymbol{B}-\boldsymbol{E})$ and IHCS $(\boldsymbol{F}-\boldsymbol{K})$ at P18. The rows are numbered $1-3$, starting with the tallest. The geometry of the bundle and the relative positioning of stereocilia in $P j v k^{-/-}$and Pjvk ${ }^{+/-} \mathrm{OHCs}(\boldsymbol{B}-\boldsymbol{C})$ and IHCs $(\boldsymbol{F}-\boldsymbol{G})$. A series of adjacent, tallest row stereocilia of an $\mathrm{OHC}(\boldsymbol{D}, \boldsymbol{E})$, cut at and around the insertion point, reveals normal-looking, centrally located, electron-dense rootlet material. IHC rootlets also appear normal at the insertion point level $(\boldsymbol{H}, \boldsymbol{I})$ and higher, close to the wide end of the taper region $(\boldsymbol{J}, \boldsymbol{K})$. Some stereocilia contain two rootlet branches (asterisks). $\mathbf{L}-\boldsymbol{P}$, Longitudinal sections through $\mathrm{P} 30$ stereocilia reveal normal rootlets, extending into the cuticular plate of $0 \mathrm{HCS}$ $\left(\boldsymbol{L}, \boldsymbol{M}\right.$, white arrows) and IHCs (N-P). No abnormalities were observed in the taper region of Pjvk $^{-/-}$stereocilia (black arrows). Scale bars: $\boldsymbol{A}, 10 \mu \mathrm{m} ; \boldsymbol{B}-\boldsymbol{P}, 500 \mathrm{~nm}$.

core, as previously noted (Furness et al., 2008). Some rootlets extended all across the cuticular plate (Fig. 10O). We conclude that pejvakin, unlike TRIOBP-4/5 (Kitajiri et al., 2010), is not essential for the formation of stereocilia rootlets.
Pejvakin regulates maintenance of shorter row stereocilia

No significant loss of OHCs was observed in Pjvk ${ }^{-1-}$ mice at $\mathrm{P} 10$, whereas, at P30, it was mostly confined to the basal region of the cochlea (Fig. 4E-J). Likewise, IHCs were present in Pjvk ${ }^{-1-}$ 
A
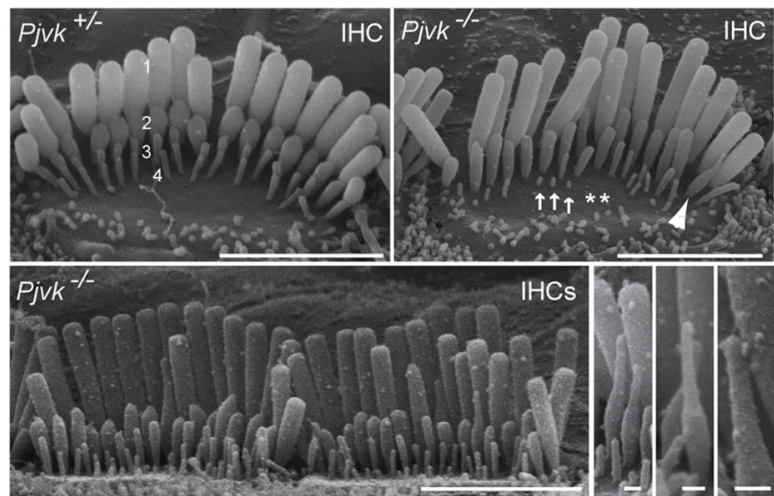

B
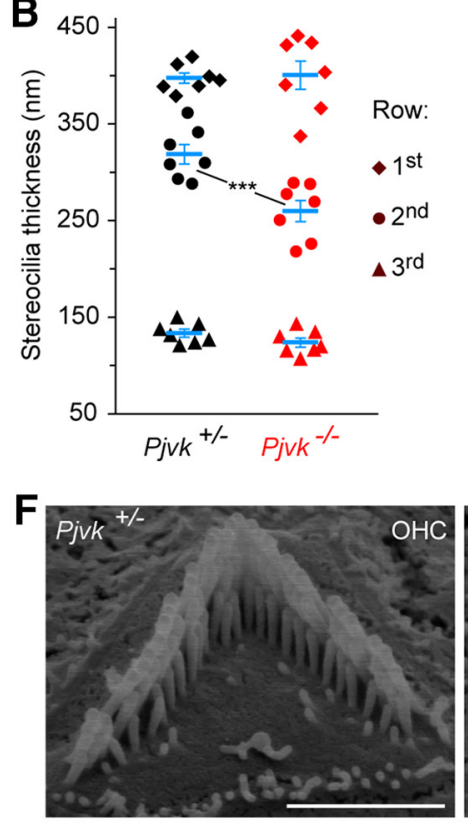

C

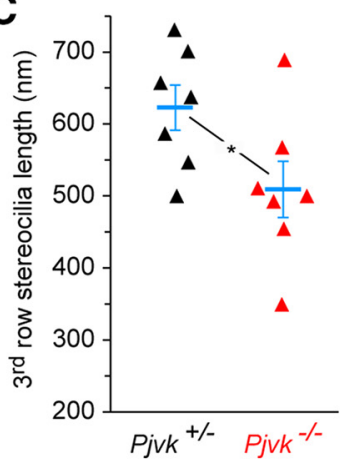

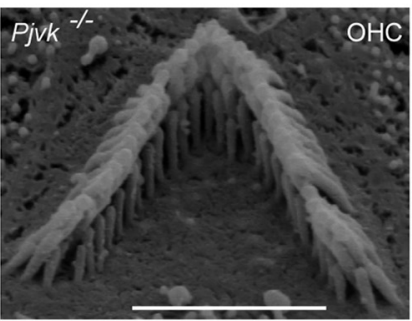
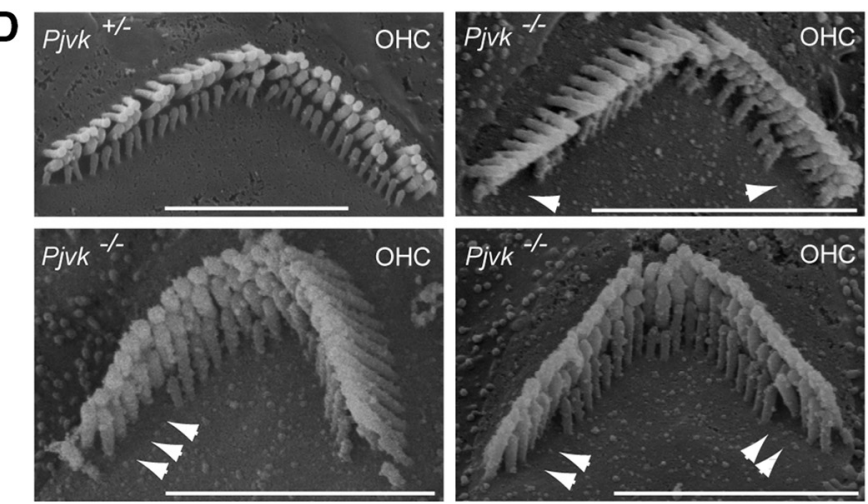

E
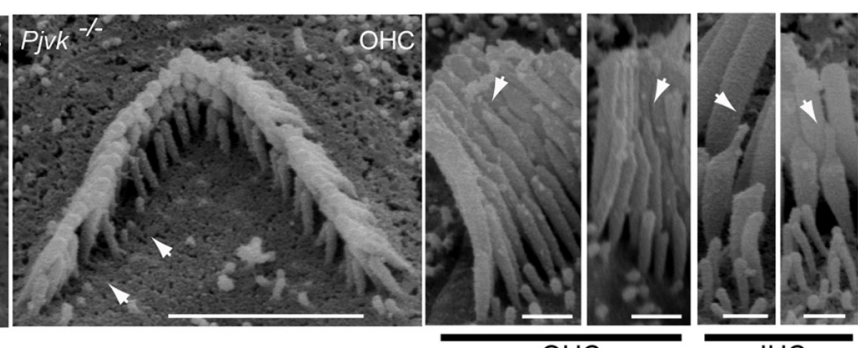

$\mathrm{OHC}$

$\mathrm{IHC}$

Figure 11. Structural defects in shorter row stereocilia of Pjvk ${ }^{-/-}$hair cells. A, SEM micrographs of IHC bundles at P3O (mediobasal turn). Pjvk ${ }^{-/-}$IHC stereociliary bundles exhibit abnormally short (arrows) or missing (asterisks) fourth row stereocilia and second row stereocilia with elongated tips (arrowhead). Second row tip shapes are variable (bottom) but can still accommodate a tip link (bottom right inset). B, Quantitation of stereocilia thickness. The thickness of IHC second row stereocilia is selectively decreased. C, Height of third row stereocilia. D, Pjvk ${ }^{-1-}$ OHCs lack multiple third row stereocilia (arrowheads). $E$, OHC third row stereocilia count compared with the first row at P30 and P11 (expressed as percentage). One-way ANOVA showed no significant difference between mice of the same genotype (Pjvk $\left.{ }^{+/-}: n=18, n=8, n=23, F=0.1, F_{\text {crit }}=3.2 ; P_{j j k}{ }^{-/-}: n=6, n=16, n=12, F=1.7, F_{\text {crit }}=3.3\right)$. Combining Pjvk ${ }^{+/-}$and Pjvk ${ }^{-/-}$mice in the analysis showed significant difference between genotypes $\left(F=16.7, F_{\text {crit }}=2.3, p=4 \times 10^{-11}\right) \cdot \boldsymbol{B}, \boldsymbol{C}, \boldsymbol{E}$, Each data point represents mean thickness $(\boldsymbol{B})$, length $(\boldsymbol{C})$, or count $(\boldsymbol{E})$ of stereocilia of a given row in a cell. Blue bars represent mean \pm SEM. ${ }^{* * *} p<0.001$ (ANOVA followed by post hoc $t$ test). ${ }^{*} p<0.05$ (ANOVA followed by post hoc $t$ test). $F$, SEM micrographs of hair cells at P11 show similar structural defects. Whereas many medial turn bundles appear normal (second image), others have short or missing third row stereocilia (third image, arrowheads). 0 ccasional slight second row stereocilia tip deformation in $\mathrm{OHCs}$ and IHCs is visible (images $4-7$, arrowheads). Scale bars: $\boldsymbol{A}, 3 \mu \mathrm{m}$ (images $1-3$ ) and $200 \mathrm{~nm}$ (images $4-6$ ); $\boldsymbol{D}, 3 \mu \mathrm{m} ; \boldsymbol{F}, 3 \mu \mathrm{m}$ (images $1-3$ ) and 500 $\mathrm{nm}$ (images 4-7).

mice at P30 and did not display any obvious signs of degeneration (Fig. 4E-I), except for the most basal "hook" region (Fig. $4 K-L$ ), indicating that hearing loss across frequencies may be due to functional defects or subtle structural anomalies in hair cells. We therefore performed a more detailed survey of stereocilia ultrastructure to delineate the mechanisms contributing to hair cell degeneration. Upon closer inspection, we observed that, in IHCs of $P j v k^{-1-}$ mice, the shortest stereocilia of the fourth row were almost completely missing and stereocilia of the second row frequently displayed abnormally thin and elongated tips (Fig. 11A). In addition, the thickness of second row stereocilia was reduced (Fig. 11B) and the height of third row stereocilia was decreased (Fig. 11C). Structural abnormalities in shorter row stereocilia were also observed in $\mathrm{OHCs}$ of $P j v k^{-/-}$mice. Multiple stereocilia of the third row were missing, predominantly at the wings of the hair bundle (Fig. 11D, arrowheads). This hair bundle phenotype was observed both at the basal (top) and medial cochlear turn (bottom). To quantify these differences, we counted third and first row stereocilia from multiple OHCs in $\mathrm{Pjvk}^{+/-}$and $\mathrm{Pjvk^{-/- }}$ ( $n=3$ mice per genotype). The ratio of third to first row stereocilia was severely decreased in $P j v k^{-1-}$ mice at P30 (Fig. 11E, Mice 1-4). A small but significant decrease was also observed at P11 (Fig. 11E, Mouse 5, 6). At this early age, some OHCs appeared normal (Fig. $11 F$, panel 2), whereas in others third row stereocilia were either missing or severely reduced in length (Fig. $11 \mathrm{~F}$, panel 3 , arrows). In addition, stereocilia in some of the IHCs and OHCs exhibited overelongated tips (Fig. 11F, panels 4-7), although this phenotype was rarely observed at P11. Selective degeneration of shorter row stereocilia combined with aberrant tip morphology has also been reported in mice deficient for the hair-cell cytoskel- 

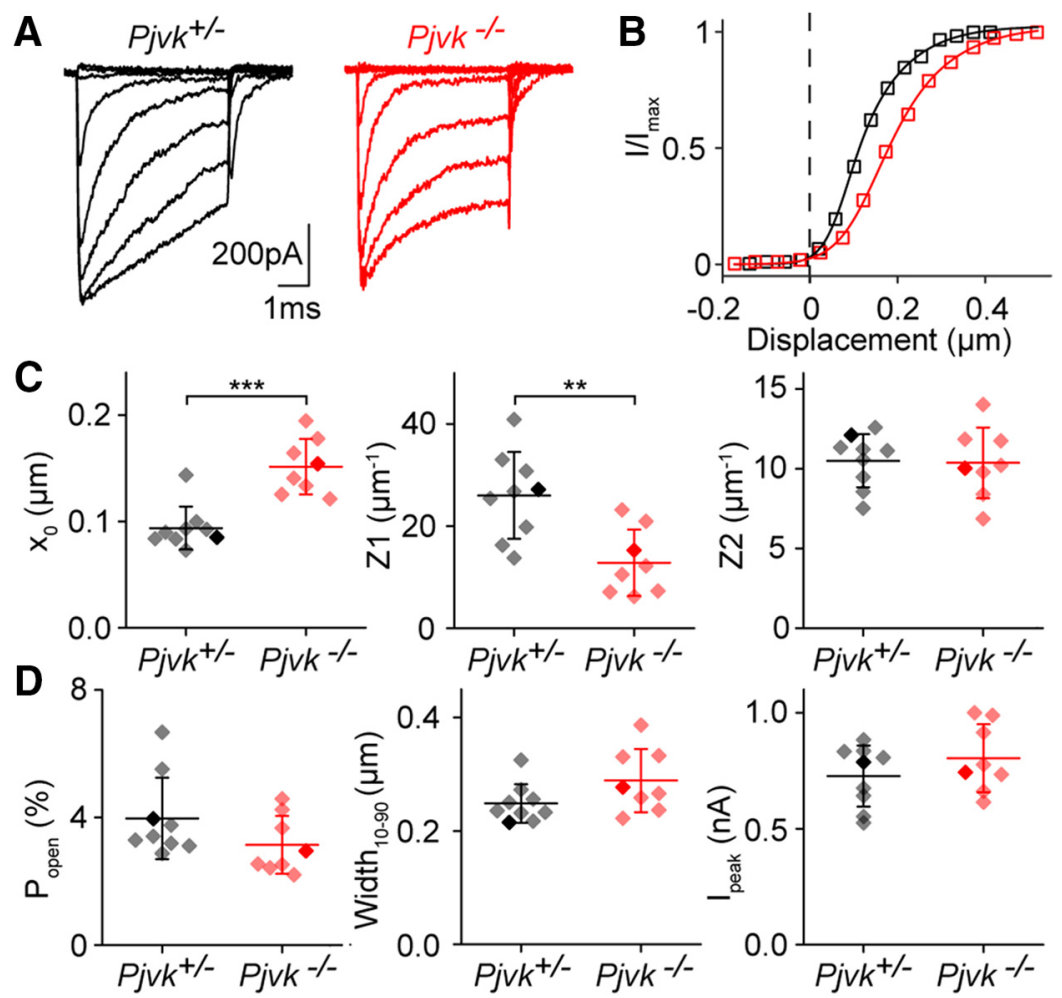

Figure 12. $\quad P_{j v k^{-/-}} \mathrm{OHCS}$ exhibit rightward shifted activation curves. $A$, Current traces recorded from an exemplary Pjvk $^{+1-}$ (black) and Pjvk ${ }^{-1-}$ (red) $\mathrm{OHC}$ in response to stepwise bundle deflection exhibit similar kinetics. $\boldsymbol{B}$, Normalized current-displacement curves for an exemplary Pjvk ${ }^{+/-}$and Pjvk ${ }^{-1-}$ OHC. C, Summary plots of the three parameters characterizing current-displacement curve, the set point $\left(x_{0}\right)$, and the slopes $\left(Z_{1}\right.$ and $\left.Z_{2}\right)$ indicate decreased deflection sensitivity of MET current in Pjvk ${ }^{-1-}$ mice. Each data point represents the result from a separate mouse. Data points corresponding to the exemplary recordings from $\boldsymbol{A}$ and $\boldsymbol{B}$ are highlighted. ${ }^{* *} p<0.005$ (two-tailed $t$ test). ${ }^{* * *} p<0.001$ (two-tailed $t$ test). $\boldsymbol{D}$, Summary plots of resting open probability $\left(\mathrm{P}_{\text {open }}\right)$, the width of bundle displacement corresponding to the $10 \%-90 \%$ activation range (Width $\left.{ }_{10-90}\right)$, and the peak current recorded for maximal bundle deflection $\left(I_{\text {peak }}\right.$ ) show no significant difference between genotypes.

etal proteins, myosin 15 isoform 1 (Fang et al., 2015) and Esp8L2 (Furness et al., 2013). These findings indicate that pejvakin is essential for maintaining shorter row stereocilia, possibly by modulating F-actin stability in hair bundles.

\section{Pejvakin deficiency decreases deflection sensitivity of MET machinery in OHCs}

The localization pattern of pejvakin in injectoporated hair cells prompted us to analyze the extent to which MET was affected in Pjvk ${ }^{-1-}$ hair cells. To determine whether hair cell function was affected before the onset of hearing, we recorded whole-cell mechanotransducer currents in P7-P10 OHCs from the apical turn of the cochlea using bundle deflections with a stiff probe. Both Pjvk ${ }^{-/+}$and Pjvk $k^{-1-}$ OHCs displayed characteristic rapid inward transducer currents, which subsequently adapted with the expected fast and slow time constants (Fig. 12A). The normalized activation curve, which reflects the dependence of the current on the magnitude of deflection, showed a rightward shift and altered slope parameter (Fig. 12 B,C), indicating that greater bundle deflection is necessary to elicit the same current in Pjvk ${ }^{-1-}$ mice. No significant difference was observed for the current recorded at maximal deflection $\left(\mathrm{I}_{\text {peak }} ;\right.$ Fig. $\left.12 D\right)$. The lack of a difference between the peak amplitudes of the transducer currents in Pjvk ${ }^{-/+}$and Pjvk ${ }^{-1-}$ OHCs at maximum deflection is consistent with the reported normal peak currents in sirtaki mice (Xiong et al., 2012), and indicates that the total number of MET channels and single-channel conductance are similar in mutants and controls. Although the differences observed in the resting open probability of MET channels and the deflection range that corresponds to the current change from $10 \%$ to $90 \%$ of its maximal deflection value did not reach significance, they show the correct trend to support the change in set point and altered slope parameter (Fig. 12D). These changes could be explained by an increased elasticity in the tip-link/channel complex or the stereocilia tips. The latter model is particularly intriguing in view of the aberrant tip morphology in Pjvk ${ }^{-1-}$ mice.

\section{Discussion}

The precise assembly of the ordered staircase structure of the hair bundle is critical for mechanotransduction and requires sophisticated regulatory mechanism to control stereocilia elongation, thickening, and resorption of excess stereocilia (Manor and Kachar, 2008). Although studies of hair bundle phenotypes in mutant mice have identified many of the actin-regulatory mechanisms that mediate stereocilia elongation during development, it is likely that similar active processes are required to maintain the precisely registered stereocilia heights throughout life. Here, we report that pejvakin, a protein that has previously been linked to auditory neuropathy and cochlear deafness, is not essential in auditory neurons for normal hearing in mice. Instead, our findings provide evidence that pejvakin acts cellautonomously in hair cells to maintain normal stereocilia staircase-structure and mechanotransduction. In injectoporated hair cells, pejvakin is localized at the stereocilia rootlets, and its C-terminal domain binds to the common part of the rootlet components TRIOBP-1 and -5 (Kitajiri et al., 2010). In the absence of pejvakin, hair cells develop hair bundles with normal rootlets but exhibit fewer and malformed shorter rows stereocilia and reduced sensitivity in their mechanotransduction responses. We conclude that pejvakin is required for the maintenance of mechanotransducing stereocilia and that deafness in Pjvk ${ }^{-1-}$ mice and DFNB59 patients likely occurs as a consequence of functional defects in auditory hair cells.

Previous studies have shown that stereocilia of Triobp-4/5deficient mice fail to assemble rootlets (Kitajiri et al., 2010). Whereas TRIOBP-5 is localized at rootlets, TRIOBP-4 is distributed along stereocilia (Kitajiri et al., 2010), suggesting that the C-terminal domain might anchor TRIOBP-5 at rootlets. Consistent with this idea, we found that TRIOBP-1, which corresponds to the $\mathrm{C}$ terminus of TRIOBP-5, exclusively localizes to the base of stereocilia in injectoporated hair cells. In analogy to TRIOBP-5, the C-terminal domain of pejvakin is critical for rootlet localization, as evidenced by the disruption of this pattern by the C-terminal sirtaki (p.K290X) deletion and p.C343S missense mutations. The C-terminal domain of pejvakin binds to and colocalizes with the coiled-coil domain of TRIOBP-1 in heterolo- 
gous cells, raising the possibility that pejvakin associates with rootlets via binding to TRIOBP. Notably, the GSDM-N domains of all gasdermins, except for pejvakin, bear intrinsic cytotoxic activity (Op de Beeck et al., 2011; Shi et al., 2015). We found that the N-terminal domain (aa 1-240) of pejvakin is localized along stereocilia in transfected hair cells as well as F-actin and filopodia in HeLa cells. Filopodia, like stereocilia, are cylindrical extensions of the plasma membrane that contain a bundle of parallel actin filaments at their core (Mattila and Lappalainen, 2008). Our findings suggest that the GSDM-N domain of pejvakin may have diverged significantly from other gasdermins, possibly to mediate interactions with the actin cytoskeleton or its associated proteins.

The precise formation and maintenance of the hair bundle's staircase organization are critical for its mechanosensory function. We show that alterations in hair bundle structure and eventual degeneration of hair cells in $P j v k^{-1-}$ mice are associated with profound hearing loss across the entire frequency range. A remarkable finding is the selective loss of the shortest row stereocilia in OHCs at P30, accompanied by a decrease in width and length of shorter rows stereocilia and overextended tips in IHCs. The hair bundle phenotype suggests that actin polymerization or filament maintenance is selectively affected in mechanotransducing stereocilia of both hair cell types. Several hypotheses as to how the loss of pejvakin causes stereocilia degeneration are plausible. Pejvakin may regulate actin assembly at the barbed ends of elongating actin filaments. However, at least in immature OHCs, GFP-pejvakin was predominantly localized at rootlets and only occasionally detected near stereocilia tips, the site of actin monomer addition. Alternatively, pejvakin at rootlets may direct the trafficking of actin-binding proteins, such as myosins and their cargo proteins into stereocilia. Indeed, mutations in several actin-binding proteins, including Eps8L2 (Furness et al., 2013) and myosin 15 isoform 1 (Fang et al., 2015), cause hair-bundle anomalies similar to the phenotype observed in $\mathrm{Pjvk}^{-1-}$ mice, with selective loss of shorter row stereocilia. Of note, myosin 15 isoform 1, which localizes to the tips of shorter row stereocilia, can affect tip shape in a manner highly reminiscent to the phenotype observed in Pjvk ${ }^{-1-}$ mice (Fang et al., 2015). It will be interesting to define in the future the extent to which pejvakin functionally interacts with these and other actin-binding proteins that regulate stereocilia elongation.

Recent studies have suggested that hypersensitivity to sound, due to peroxisomal defects, plays a role in the degeneration of hair cells and neurons in Pjvk ${ }^{-1}$ mice (Delmaghani et al., 2015). We show here that hair cells in Pjvk ${ }^{-1-}$ mice develop morphological and functional defects before the onset of hearing. Abnormal MET responses and loss of mechanotransducing stereocilia are clearly present by $\mathrm{P} 11$, and thus unlikely the result of noise. In P7-P10 Pjvk ${ }^{-1-}$ mice, OHCs have normal transduction-current amplitudes, suggesting that critical components of the MET machinery are transported into stereocilia. The shift in the $\mathrm{I}(\mathrm{X})$ curve, however, demonstrates that the sensitivity of the MET currents to hair bundle displacement is decreased, indicating that pejvakin is required for normal mechanotransduction by OHCs. Based on the distribution of pejvakin in stereocilia and the overextended stereocilia tips in $\mathrm{Pjvk}^{-1-}$ mice, it is possible that effects on mechanotransduction were caused by defects in the actin core cytoskeleton or actin-membrane association at stereocilia tips, which contribute to the stiffness of the hypothetical gating spring element attached to the MET channel (Corey and Hudspeth, 1983; Howard and Hudspeth, 1987).

A recently proposed model for pejvakin in peroxisomal proliferation was based on the generation of a monoclonal pejvakin antibody (Delmaghani et al., 2015). Although commercially available antibodies failed to detect endogenous pejvakin in mouse tissue, we found that they recognize exogenous pejvakin in HeLa cells. Surprisingly, neither GFP-tagged nor untagged pejvakin colocalized with the peroxisomal marker PMP70 when expressed in HeLa cells or cochlear hair cells. The use of hair cell injectoporation technique (Xiong et al., 2014) allowed us to detect pejvakin in the basal compartment of stereocilia and probe the effects of DFNB59 mutations on pejvakin localization. This important feature would have likely been missed using only antibodies, which specifically detected pejvakin in cell lines but not at hair cell rootlets. Indeed, when we expressed GFP-pejvakin in hair cells, the fusion protein could be detected at the rootlets with an antiGFP antibody but not by antibodies against different epitopes in pejvakin (data not shown), suggesting that, within densely packed rootlet complexes, these epitopes may be masked by the presence of pejvakin-associated proteins. Similarly, pejvakinspecific antibodies were unable to penetrate the dense round structures formed in HeLa cells coexpressing TRIOBP1 and pejvakin, producing a characteristic ring-like signal.

Our studies show that genetic ablation of pejvakin in auditory neurons has no effect on ABR thresholds and latencies, which is consistent with the lack of detectable levels of pejvakin mRNA in these cells in wild-type mice. Initial expression studies with a polyclonal antibody indicating neuronal expression (Delmaghani et al., 2006) were later put into question (Delmaghani et al., 2015), whereas in recent studies with a pejvakin monoclonal antibody neuronal expression has not been reported (Delmaghani et al., 2015). Notably, ABRs were unaffected in 2-month-old Pjvk ${ }^{\mathrm{fl} / \mathrm{fl}} \mathrm{Ngn1-CreER^{ \textrm {T } 2 }}$ mice exposed to the same natural acoustic environment as $\mathrm{Pjvk}^{-1-}$ mice. Furthermore, controlled acoustic stimulation failed to detect the recently proposed hypersensitivity of auditory neurons to noise (Delmaghani et al., 2015). These findings raise the question as to how pejvakin mutations might cause ANSD.

In agreement with a previous study (Delmaghani et al., 2015), we show here that hair cell degeneration in pejvakin loss-offunction mouse models is not limited to OHCs. Given the absence of a phenotype in the neuron-specific Pjvk knock-out mice, it seems plausible that IHC dysfunction contributes to hearing loss in DFNB59 patients with intact OAEs. Intriguingly, we observed that p.C343S and p.K290X mutations, which disrupt OAEs in human patients and sirtaki mice, respectively, abolish the localization of pejvakin at the base of stereocilia, indicating that its presence at rootlets is critical for OHC function. No morphological abnormalities in hair cells of p.R183W knock-in mice have been described (Delmaghani et al., 2006). ANSD-linked mutations may therefore have a subtler effect on pejvakin and predominantly affect IHC function or lead to a slower progression of OHC degeneration. Indeed, the p.R183W mutation can cause hearing loss with or without normal OAE responses in different individuals (Delmaghani et al., 2006; Collin et al., 2007), suggesting that OAEs may disappear with the progression of the disease or be dependent on additional genetic factors. We conclude that pejvakin plays a vital role in hair cells and is required to sustain OHC activity and survival. Finally, our findings have therapeutic implications. The distinction between ANSD and a cochlear defect is important as cochlear implants may be of marginal value in patients with ANSD caused by cochlear nerve damage but have proven effective for treatment of individuals with hair cell-related deafness. 


\section{References}

Assad JA, Shepherd GM, Corey DP (1991) Tip-link integrity and mechanical transduction in vertebrate hair cells. Neuron 7:985-994. CrossRef Medline

Astuto LM, Bork JM, Weston MD, Askew JW, Fields RR, Orten DJ, Ohliger SJ, Riazuddin S, Morell RJ, Khan S, Riazuddin S, Kremer H, van Hauwe P, Moller CG, Cremers CW, Ayuso C, Heckenlively JR, Rohrschneider K, Spandau U, Greenberg J, et al. (2002) CDH23 mutation and phenotype heterogeneity: a profile of 107 diverse families with Usher syndrome and nonsyndromic deafness. Am J Hum Genet 71:262-275. CrossRef Medline

Beurg M, Fettiplace R, Nam JH, Ricci AJ (2009) Localization of inner hair cell mechanotransducer channels using high-speed calcium imaging. Nat Neurosci 12:553-558. CrossRef Medline

Bradshaw NJ, Bader V, Prikulis I, Lueking A, Müllner S, Korth C (2014) Aggregation of the protein TRIOBP-1 and its potential relevance to schizophrenia. PLoS One 9:e111196. CrossRef Medline

Campbell RE, Tour O, Palmer AE, Steinbach PA, Baird GS, Zacharias DA, Tsien RY (2002) A monomeric red fluorescent protein. Proc Natl Acad Sci U S A 99:7877-7882. CrossRef Medline

Chevalier C, Nicolas JF, Petit AC (2014) Preparation and delivery of 4-hydroxy-tamoxifen for clonal and polyclonal labeling of cells of the surface ectoderm, skin, and hair follicle. Methods Mol Biol 1195:239245. CrossRef Medline

Coate TM, Raft S, Zhao X, Ryan AK, Crenshaw EB 3rd, Kelley MW (2012) Otic mesenchyme cells regulate spiral ganglion axon fasciculation through a Pou3f4/EphA4 signaling pathway. Neuron 73:49-63. CrossRef Medline

Coate TM, Spita NA, Zhang KD, Isgrig KT, Kelley MW (2015) Neuropilin2/Semaphorin-3F-mediated repulsion promotes inner hair cell innervation by spiral ganglion neurons. eLife 4 .

Collin RW, Kalay E, Oostrik J, Caylan R, Wollnik B, Arslan S, den Hollander AI, Birinci Y, Lichtner P, Strom TM, Toraman B, Hoefsloot LH, Cremers CW, Brunner HG, Cremers FP, Karaguzel A, Kremer H (2007) Involvement of DFNB59 mutations in autosomal recessive nonsyndromic hearing impairment. Hum Mutat 28:718-723. CrossRef Medline

Corey DP, Hudspeth AJ (1983) Kinetics of the receptor current in bullfrog saccular hair cells. J Neurosci 3:962-976. Medline

Delmaghani S, del Castillo FJ, Michel V, Leibovici M, Aghaie A, Ron U, Van Laer L, Ben-Tal N, Van Camp G, Weil D, Langa F, Lathrop M, Avan P, Petit C (2006) Mutations in the gene encoding pejvakin, a newly identified protein of the afferent auditory pathway, cause DFNB59 auditory neuropathy. Nat Genet 38:770-778. CrossRef Medline

Delmaghani S, Defourny J, Aghaie A, Beurg M, Dulon D, Thelen N, Perfettini I, Zelles T, Aller M, Meyer A, Emptoz A, Giraudet F, Leibovici M, Dartevelle S, Soubigou G, Thiry M, Vizi ES, Safieddine S, Hardelin JP, Avan P, et al. (2015) Hypervulnerability to sound exposure through impaired adaptive proliferation of peroxisomes. Cell 163:894-906. CrossRef Medline

Fang Q, Indzhykulian AA, Mustapha M, Riordan GP, Dolan DF, Friedman TB, Belyantseva IA, Frolenkov GI, Camper SA, Bird JE (2015) The 133$\mathrm{kDa} \mathrm{N}$-terminal domain enables myosin 15 to maintain mechanotransducing stereocilia and is essential for hearing. eLife 4 .

Furness DN, Mahendrasingam S, Ohashi M, Fettiplace R, Hackney CM (2008) The dimensions and composition of stereociliary rootlets in mammalian cochlear hair cells: comparison between high- and lowfrequency cells and evidence for a connection to the lateral membrane. J Neurosci 28:6342-6353. CrossRef Medline

Furness DN, Johnson SL, Manor U, Rüttiger L, Tocchetti A, Offenhauser N, Olt J, Goodyear RJ, Vijayakumar S, Dai Y, Hackney CM, Franz C, Di Fiore PP, Masetto S, Jones SM, Knipper M, Holley MC, Richardson GP, Kachar B, Marcotti W (2013) Progressive hearing loss and gradual deterioration of sensory hair bundles in the ears of mice lacking the actin-binding protein Eps8L2. Proc Natl Acad Sci U S A 110:13898-13903. CrossRef Medline

Graus-Porta D, Blaess S, Senften M, Littlewood-Evans A, Damsky C, Huang Z, Orban P, Klein R, Schittny JC, Müller U (2001) Betal-class integrins regulate the development of laminae and folia in the cerebral and cerebellar cortex. Neuron 31:367-379. CrossRef Medline

Grillet N, Schwander M, Hildebrand MS, Sczaniecka A, Kolatkar A, Velasco J, Webster JA, Kahrizi K, Najmabadi H, Kimberling WJ, Stephan D, Bahlo M, Wiltshire T, Tarantino LM, Kuhn P, Smith RJ, Müller U (2009) Mutations in LOXHD1, an evolutionarily conserved stereociliary protein, disrupt hair cell function in mice and cause progressive hearing loss in humans. Am J Hum Genet 85:328-337. CrossRef Medline

Howard J, Hudspeth AJ (1987) Mechanical relaxation of the hair bundle mediates adaptation in mechanoelectrical transduction by the bullfrog's saccular hair cell. Proc Natl Acad Sci U S A 84:3064-3068. CrossRef Medline

Howard J, Hudspeth AJ (1988) Compliance of the hair bundle associated with gating of mechanoelectrical transduction channels in the bullfrog's saccular hair cell. Neuron 1:189-199. CrossRef Medline

Kazmierczak M, Harris SL, Kazmierczak P, Shah P, Starovoytov V, Ohlemiller KK, Schwander M (2015) Progressive hearing loss in mice carrying a mutation in Usp53. J Neurosci 35:15582-15598. CrossRef Medline

Kemp DT (2002) Otoacoustic emissions, their origin in cochlear function, and use. Br Med Bull 63:223-241. CrossRef Medline

Kitajiri S, Sakamoto T, Belyantseva IA, Goodyear RJ, Stepanyan R, Fujiwara I, Bird JE, Riazuddin S, Ahmed ZM, Hinshaw JE, Sellers J, Bartles JR, Hammer JA 3rd, Richardson GP, Griffith AJ, Frolenkov GI, Friedman TB (2010) Actin-bundling protein TRIOBP forms resilient rootlets of hair cell stereocilia essential for hearing. Cell 141:786-798. CrossRef Medline

Koundakjian EJ, Appler JL, Goodrich LV (2007) Auditory neurons make stereotyped wiring decisions before maturation of their targets. J Neurosci 27:14078-14088. CrossRef Medline

Madisen L, Zwingman TA, Sunkin SM, Oh SW, Zariwala HA, Gu H, Ng LL, Palmiter RD, Hawrylycz MJ, Jones AR, Lein ES, Zeng H (2010) A robust and high-throughput Cre reporting and characterization system for the whole mouse brain. Nat Neurosci 13:133-140. CrossRef Medline

Manor U, Kachar B (2008) Dynamic length regulation of sensory stereocilia. Semin Cell Dev Biol 19:502-510. CrossRef Medline

Mattila PK, Lappalainen P (2008) Filopodia: molecular architecture and cellular functions. Nat Rev Mol Cell Biol 9:446-454. CrossRef Medline

Mujtaba G, Bukhari I, Fatima A, Naz S (2012) A p.C343S missense mutation in PJVK causes progressive hearing loss. Gene 504:98-101. CrossRef Medline

Op de Beeck K, Van Camp G, Thys S, Cools N, Callebaut I, Vrijens K, Van Nassauw L, Van Tendeloo VF, Timmermans JP, Van Laer L (2011) The DFNA5 gene, responsible for hearing loss and involved in cancer, encodes a novel apoptosis-inducing protein. Eur J Hum Genet 19:965-973. CrossRef Medline

Pickles JO, Comis SD, Osborne MP (1984) Cross-links between stereocilia in the guinea pig organ of Corti, and their possible relation to sensory transduction. Hear Res 15:103-112. CrossRef Medline

Rappoport JZ, Simon SM (2008) A functional GFP fusion for imaging clathrin-mediated endocytosis. Traffic 9:1250-1255. CrossRef Medline

Rehman AU, Morell RJ, Belyantseva IA, Khan SY, Boger ET, Shahzad M, Ahmed ZM, Riazuddin S, Khan SN, Riazuddin S, Friedman TB (2010) Targeted capture and next-generation sequencing identifies C9orf75, encoding taperin, as the mutated gene in nonsyndromic deafness DFNB79. Am J Hum Genet 86:378-388. CrossRef Medline

Saeki N, Kuwahara Y, Sasaki H, Satoh H, Shiroishi T (2000) Gasdermin (Gsdm) localizing to mouse Chromosome 11 is predominantly expressed in upper gastrointestinal tract but significantly suppressed in human gastric cancer cells. Mamm Genome 11:718-724. CrossRef Medline

Schwander M, Sczaniecka A, Grillet N, Bailey JS, Avenarius M, Najmabadi H, Steffy BM, Federe GC, Lagler EA, Banan R, Hice R, Grabowski-Boase L, Keithley EM, Ryan AF, Housley GD, Wiltshire T, Smith RJ, Tarantino LM, Müller U (2007) A forward genetics screen in mice identifies recessive deafness traits and reveals that pejvakin is essential for outer hair cell function. J Neurosci 27:2163-2175. CrossRef Medline

Senften M, Schwander M, Kazmierczak P, Lillo C, Shin JB, Hasson T, Géléoc GS, Gillespie PG, Williams D, Holt JR, Müller U (2006) Physical and functional interaction between protocadherin 15 and myosin VIIa in mechanosensory hair cells. J Neurosci 26:2060-2071. CrossRef Medline

Shi J, Zhao Y, Wang K, Shi X, Wang Y, Huang H, Zhuang Y, Cai T, Wang F, Shao F (2015) Cleavage of GSDMD by inflammatory caspases determines pyroptotic cell death. Nature 526:660-665. CrossRef Medline

Starr A, Picton TW, Sininger Y, Hood LJ, Berlin CI (1996) Auditory neuropathy. Brain 119:741-753. CrossRef Medline

Tilney LG, Tilney MS, DeRosier DJ (1992a) Actin filaments, stereocilia, and hair cells: how cells count and measure. Annu Rev Cell Biol 8:257-274. CrossRef Medline

Tilney LG, Cotanche DA, Tilney MS (1992b) Actin filaments, stereocilia 
and hair cells of the bird cochlea: VI. How the number and arrangement of stereocilia are determined. Development 116:213-226. Medline

Tronche F, Kellendonk C, Kretz O, Gass P, Anlag K, Orban PC, Bock R, Klein R, Schütz G (1999) Disruption of the glucocorticoid receptor gene in the nervous system results in reduced anxiety. Nat Genet 23:99-103. CrossRef Medline

Xiong W, Grillet N, Elledge HM, Wagner TF, Zhao B, Johnson KR, Kazmierczak P, Müller U (2012) TMHS is an integral component of the mechanotransduction machinery of cochlear hair cells. Cell 151:1283-1295. CrossRef Medline

Xiong W, Wagner T, Yan L, Grillet N, Müller U (2014) Using injectoporation to deliver genes to mechanosensory hair cells. Nat Protoc 9:24382449. CrossRef Medline

Yasunaga S, Grati M, Cohen-Salmon M, El-Amraoui A, Mustapha M, Salem
N, El-Zir E, Loiselet J, Petit C (1999) A mutation in OTOF, encoding otoferlin, a FER-1-like protein, causes DFNB9, a nonsyndromic form of deafness. Nat Genet 21:363-369. CrossRef Medline

Zhang J, Dublin P, Griemsmann S, Klein A, Brehm R, Bedner P, Fleischmann BK, Steinhäuser C, Theis M (2013) Germline recombination activity of the widely used hGFAP-Cre and nestin-Cre transgenes. PLoS One 8:e82818. CrossRef Medline

Zhao FF, Ji YB, Wang DY, Lan L, Han MK, Li Q, Zhao Y, Rao S, Han D, Wang QJ (2011) Phenotype-genotype correlation in 295 Chinese deaf subjects with biallelic causative mutations in the GJB2 gene. Genet Test Mol Biomarkers 15:619-625. CrossRef Medline

Zheng QY, Johnson KR, Erway LC (1999) Assessment of hearing in 80 inbred strains of mice by ABR threshold analyses. Hear Res 130:94-107. CrossRef Medline 